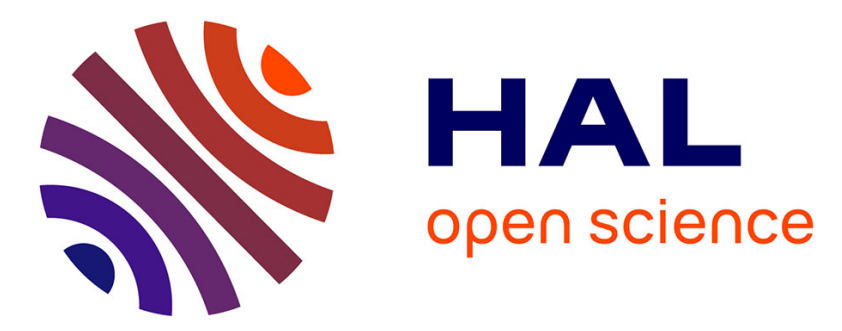

\title{
In vivo identification of putative CPK5 substrates in Arabidopsis thaliana
}

Tiffany Yip Delormel, Liliana Avila-Ospina, Marlène Davanture, Michel Zivy, Julien Lang, Nicolas Valentin, Naganand Rayapuram, Heribert Hirt, Jean Colcombet, Marie Boudsocq

\section{To cite this version:}

Tiffany Yip Delormel, Liliana Avila-Ospina, Marlène Davanture, Michel Zivy, Julien Lang, et al.. In vivo identification of putative CPK5 substrates in Arabidopsis thaliana. Plant Science, 2022, 314, pp.111121. 10.1016/j.plantsci.2021.111121 . hal-03462313

\section{HAL Id: hal-03462313 https://hal.science/hal-03462313}

Submitted on 1 Dec 2021

HAL is a multi-disciplinary open access archive for the deposit and dissemination of scientific research documents, whether they are published or not. The documents may come from teaching and research institutions in France or abroad, or from public or private research centers.
L'archive ouverte pluridisciplinaire HAL, est destinée au dépôt et à la diffusion de documents scientifiques de niveau recherche, publiés ou non, émanant des établissements d'enseignement et de recherche français ou étrangers, des laboratoires publics ou privés. 


\section{In vivo identification of putative CPK5 substrates in Arabidopsis thaliana}

Tiffany Yip Delormel ${ }^{a, b}$, Liliana Avila-Ospina ${ }^{a, b, 1}$, Marlène Davanture ${ }^{c}$, Michel Zivy ${ }^{c}$, Julien Lang $^{a, b}$, Nicolas Valentin ${ }^{a, b, 2}$, Naganand Rayapuram ${ }^{d}$, Heribert Hirt ${ }^{d}$, Jean Colcombet ${ }^{a, b}$ and Marie Boudsocq ${ }^{a, b}$

${ }^{a}$ Université Paris-Saclay, CNRS, INRAE, Univ Evry, Institute of Plant Sciences Paris-Saclay (IPS2), 91405 Orsay, France

${ }^{\mathrm{b}}$ Université de Paris, Institute of Plant Sciences Paris-Saclay (IPS2), 91405 Orsay, France

${ }^{c}$ Université Paris-Saclay, INRAE, CNRS, AgroParisTech, Génétique Quantitative et Évolution (GQE) - Le Moulon, 91190 Gif-sur-Yvette, France

d Center for Desert Agriculture, 4700 King Abdullah University of Science and Technology (KAUST), Thuwal, Saudi Arabia

${ }^{1}$ present address: Plateforme de Biophysique Moléculaire PFBMI, Institut Pasteur, 25-28 rue Dr. Roux, 75015 Paris, France

${ }^{2}$ present address: Institut Jacques Monod, Université de Paris, CNRS, Bâtiment Buffon, 15 rue Hélène Brion, 75205 Paris cedex 13, France

T.Y.D. (tdelormel@gmail.com), L.A.O. (liliana.avila-ospina@pasteur.fr), M.D. (marlene.davanture@inrae.fr), M.Z. (michel.zivy@inrae.fr), J.L. (julien.lang@inrae.fr), N.V. (nicolas.valentin@ijm.fr), N.R. (naganand.rayapuram@kaust.edu.sa), $\quad$ H.H. (heribert.hirt@kaust.edu.sa), J.C. (jean.colcombet@inrae.fr), M.B. (marie.boudsocq@cnrs.fr)

Corresponding author : Marie Boudsocq (marie.boudsocq@cnrs.fr)

Institute of Plant Sciences Paris-Saclay (IPS2), rue Noetzlin Bât 630, Plateau du Moulon, CS80004, 91192 Gif-sur-Yvette cedex, France 
Abstract

Calcium signaling mediates most developmental processes and stress responses in plants. Among plant calcium sensors, the calcium-dependent protein kinases display a unique structure harboring both calcium sensing and kinase responding activities. AtCPK5 is an essential member of this family in Arabidopsis that regulates immunity and abiotic stress tolerance. To understand the underlying molecular mechanisms, we implemented a biochemical approach to identify in vivo substrates of AtCPK5. We generated transgenic lines expressing a constitutively active form of AtCPK5 under the control of a dexamethasoneinducible promoter. Lines expressing a kinase-dead version were used as a negative control. By comparing the phosphoproteome of the kinase-active and kinase-dead lines upon dexamethasone treatment, we identified 5 phosphopeptides whose abundance increased specifically in the kinase-active lines. Importantly, we showed that all 5 proteins were phosphorylated in vitro by AtCPK5 in a calcium-dependent manner, suggesting that they are direct targets of AtCPK5. We also detected several interaction patterns between the kinase and the candidates in the cytosol, membranes or nucleus, consistent with the ubiquitous localization of AtCPK5. Finally, we further validated the two phosphosites S245 and S280 targeted by AtCPK5 in the E3 ubiquitin ligase ATL31. Altogether, those results open new perspectives to decipher AtCPK5 biological functions.

Key words

AtCPK5, substrates, phosphorylation, Arabidopsis

Abbreviations:

aa: amino acids; ACN: acetonitrile; CDPK: calcium-dependent protein kinase; Dex: dexamethasone; MAPK: mitogen-activated protein kinase; $\mathrm{RBOH}$ : respiratory burst oxidase homolog 


\section{Introduction}

Calcium is a ubiquitous second messenger that modulates plant responses to a myriad of developmental and environmental cues [1]. Each stimulus is believed to trigger a specific calcium rise defined by the amplitude, duration, frequency, subcellular localization and calcium store [2-4]. The specificity in calcium signaling is also achieved by the diverse calcium sensors able to decode calcium signals $[5,6]$. Among them, the calcium-dependent protein kinases (CDPKs or CPKs) display the unique feature of combining in one single protein both calcium binding via EF-hands at the C-terminal part and responding activity through the protein kinase domain $[7,8]$. Those two domains are linked by an autoinhibitory domain that maintains the protein kinase in an inactive state through intramolecular interactions $[9,10]$. Upon calcium perception, CDPKs undergo a conformational change that releases the autoinhibition and activates the kinase [11], enabling CDPKs to modify the activity, stability or localization of their targets by reversible phosphorylation, in various biological contexts. In particular, Arabidopsis AtCPK5 positively regulates immune responses, along with its homologs AtCPK6 [12]. AtCPK5 was reported to mediate plant resistance to bacteria and fungi, through the regulation of gene expression and oxidative burst [13-19]. AtCPK5 and AtCPK6 also trigger ethylene biosynthesis upon wounding and fungal infection $[20,21]$. While several WRKY transcription factors as well as the respiratory burst oxidase homolog RBOHD have been characterized as bona fide AtCPK5 substrates during plant immunity $[14,18,22,23]$, most AtCPK5 targets remain unknown.

Identifying the substrates of protein kinases is crucial to understand their biological functions in vivo. Several approaches have been developed, either based on protein-protein interaction like the yeast two-hybrid system, or on phosphorylation assays [24-26]. The strategies based on protein interactions can generate many false positives since the partner may not be a substrate. Indeed, only $46 \%$ of the partners identified in a yeast two-hybrid screen with AtCPK4 or AtCPK11 could be phosphorylated in vitro by the kinases [27]. Conversely, the candidates retrieved by in vitro kinase assays may also be irrelevant if the kinase and substrates never meet in the cell, because of distinct expression patterns and/or subcellular localizations. For example, while both StCDPK5 and SICDPK2 can phosphorylate in vitro the NADPH oxidase StRBOHB, only StCDPK5 can regulate StRBOHB in vivo at the plasma membrane, SICDPK2 being located at the Golgi [28]. Nevertheless, those approaches can still 
identify putative targets even though the relevant protein kinase isoform needs to be validated. This is especially true with large multigene families like CDPKs which comprise 34 members in Arabidopsis with overlapping functions $[8,12]$ and rather low substrate specificity in vitro even between representatives of the 4 subgroups $[25,29]$. Thus, strategies combining both aspects like in vivo phosphoproteomics are more likely to identify biologically relevant substrates, as observed for mitogen-activated protein kinases (MAPKs) and SNF1-related protein kinases 2 (SnRK2s) using knockout mutants [30-32]. To overcome mutant lethality or functional redundancy between protein kinase isoforms, gain-of-function approaches have also been implemented using inducible expression of constitutively active forms of tobacco MAPKK NtMEK2 or rapeseed MAPK BnMPK4 [33,34]. While active variants of MAPK and MAPKK are obtained by point mutations in the activation loop [35], they are generated in CDPKs by deleting the C-terminal part of the protein comprising the autoinhibitory and calcium binding domains $[9,13]$. Recently, a study using such a strategy identified the transcription factor ORE1 as an in vivo substrate of AtCPK1 involved in senescence [36]. Here, using transgenic lines expressing the constitutively active form of AtCPK5 (CPK5ac) under the control of an inducible promoter, combined with a phosphoproteomic analysis, we identified five new putative in vivo substrates of AtCPK5. We further carried out in vitro kinase assays and in vivo interaction assays to validate the candidates. Overall, our data suggest that AtCPK5 regulates target proteins in several cellular compartments and biological processes.

\section{Materials and methods}

\subsection{Plant materials and growth conditions}

Seeds of Arabidopsis thaliana ecotype Columbia (Col0) were sterilized, stratified at $4^{\circ} \mathrm{C}$ for 2 days and grown on half-strength Murashige and Skoog liquid medium (Sigma) containing $0.5 \%$ sucrose and $0.5 \mathrm{~g} / \mathrm{L} \mathrm{MES}, \mathrm{pH} 5.7(1 / 2 \mathrm{MS})$, in a controlled chamber $\left(22^{\circ} \mathrm{C}, 60 \%\right.$ relative humidity, 16 h photoperiod) for 10-14 days. For Dexamethasone (Dex) treatment, seedlings were equilibrated in fresh $1 / 2 \mathrm{MS}$ overnight before applying mock ( $0.05 \%$ final ethanol) or Dex 
at $1 \mu \mathrm{M}$ final for $1-8 \mathrm{~h}$. Seedlings were quickly dried, frozen in liquid nitrogen and stored at $80^{\circ} \mathrm{C}$. For cell death analysis, plants were grown individually on soil pellets (Jiffy) in a controlled chamber $\left(22^{\circ} \mathrm{C}, 70 \%\right.$ relative humidity, $12 \mathrm{~h}$ photoperiod) for 4 weeks. The $35 \mathrm{~S}-$ CPK5-HA transgenic line was previously described [37]. Nicotiana benthamiana plants were grown in greenhouse at $24^{\circ} \mathrm{C}$ for 4 weeks.

\subsection{Generating inducible transgenic lines}

The genomic DNA sequence of CPK5 (At4g35310) corresponding to the truncated active form (1324 nucleotides from ATG) was amplified from Arabidopsis Col0 plants using the primers listed in Supplementary Table S1 and inserted as an Xhol-Stul fragment into a dexamethasone (Dex)-inducible plant expression binary vector [14], containing an HA epitope tag at the C-terminus. A point mutation in the kinase domain of CPK5 (D221A) was introduced by directed mutagenesis using the primers listed in Supplementary Table S2 to generate the inactive dead version of CPK5. The integrity of the constructs was confirmed by sequencing before introducing the vectors into Agrobacterium tumefaciens GV3101 to transform WT Arabidopsis ColO plants using the drop-by-drop method [38]. Transgenic plants were selected on hygromycin resistance and expression of the transgene was monitored by western-blot analysis. Segregation of the resistance was analyzed in T1 and T2 generations to select transgenic lines with one T-DNA (transfer DNA) insertion at the homozygous state.

\subsection{Protein extraction and in-solution digestion}

The phosphoproteomic analysis was performed as previously described [39] on 3 biological replicates of 14-day-old seedlings (Dex:CPK5ac-WT and Dex:CPK5ac-dead) treated with Dex 1 $\mu \mathrm{M}$ for $2 \mathrm{~h}$ and $4 \mathrm{~h}$ (total 12 samples). Briefly, frozen seedlings were finely ground in liquid nitrogen and proteins were extracted in a denaturating buffer (10\% trichloroacetic acid, $0.07 \%$ Bmercaptoethanol in acetone). After $1 \mathrm{~h}$-incubation at $-20^{\circ} \mathrm{C}$, samples were centrifuged at $21000 \mathrm{~g}$ at $4^{\circ} \mathrm{C}$ for $10 \mathrm{~min}$. Pellets were washed three times in acetone containing $0.07 \%$ Bmercaptoethanol and spin-dried before solubilization in ZUT buffer (6 M 
urea, $2 \mathrm{M}$ thiourea, $10 \mathrm{mM}$ DTT, $30 \mathrm{mM}$ Tris- $\mathrm{HCl}$ pH 8.8, 0.1\% Progenta Zwitterionic Acid Labile Surfactant I) at $30 \mu \mathrm{l} / \mathrm{mg}$ of sample powder. Cell debris were eliminated by centrifugation at $16000 \mathrm{~g}$ for $25 \mathrm{~min}$. Protein concentration was determined using the 2-D Quant-kit (GE Healthcare) with bovine serum albumin (BSA) as standard. In addition to the 12 samples, internal standards were prepared by pooling $100 \mu \mathrm{g}$ of each sample $(1.2 \mathrm{mg}$ proteins in total). For each sample and internal standard, $1.2 \mathrm{mg}$ proteins were alkylated with iodoacetamide at $40 \mathrm{mM}$ final concentration for $45 \mathrm{~min}$ in the dark. The samples were then diluted to $<1 \mathrm{M}$ urea by adding $50 \mathrm{mM}$ ammonium bicarbonate. Protein digestion (sequencing grade modified trypsin, Promega) was performed at an enzyme/substrate ratio of $1: 50(\mathrm{w} / \mathrm{w})$ during overnight incubation at $37^{\circ} \mathrm{C}$, and stopped by adding trifluoroacetic acid at $0.6 \%(\mathrm{v} / \mathrm{v})$ final concentration. For label-free shotgun proteome analysis, $40 \mu \mathrm{g}$ proteins from each sample were processed according to Havé et al. [40].

\subsection{Stable isotope dimethyl labeling}

Tryptic peptides were spin-dried and resuspended in $1 \mathrm{ml}$ of $5 \%$ formic acid $(\mathrm{v} / \mathrm{v})$. Stable isotope dimethyl labeling was performed according to the on-column procedure described by Boersema et al. [41] using formaldehyde- $\mathrm{CH}_{2} \mathrm{O}$ (light labeling), formaldehyde- $\mathrm{CD}_{2} \mathrm{O}$ (intermediate labeling) or formaldehyde $-{ }^{13} \mathrm{CD}_{2} \mathrm{O}$ (heavy labeling). Each sample was loaded on a separate SepPak C18 cartridge column ( $3 \mathrm{ml}$; Waters) and washed with $0.6 \%$ acetic acid $(\mathrm{v} / \mathrm{v})$. SepPak columns were flushed five times with $1 \mathrm{ml}$ of the respective labeling reagent (50 mM sodium phosphate buffer $\mathrm{pH} 7.5$ containing $30 \mathrm{mM} \mathrm{NaBH}{ }_{3} \mathrm{CN}$ and $0.2 \% \mathrm{CH}_{2} \mathrm{O}$ or $\mathrm{CD}_{2} \mathrm{O}(\mathrm{v} / \mathrm{v})$ for light or intermediate labeling, respectively, or $30 \mathrm{mM} \mathrm{NaBD}{ }_{3} \mathrm{CN}$ and $0.2 \%$ ${ }^{13} \mathrm{CD}_{2} \mathrm{O}(\mathrm{v} / \mathrm{v})$ for heavy labeling). SepPak columns were washed with $2 \mathrm{ml}$ of $0.6 \%$ acetic acid (v/v). Labeled samples were eluted with $500 \mu$ of $0.6 \%$ acetic acid (v/v) and $80 \%$ acetonitrile $(\mathrm{ACN}, \mathrm{v} / \mathrm{v})$. Biological replicates were labeled with the intermediate and heavy isotopes whereas the internal standard was labeled with the light isotope. For each time point (Dex 2 $\mathrm{h}$ and $4 \mathrm{~h}$ ) and each biological replicate, labelled peptides from Dex:CPK5ac-WT, Dex:CPK5acdead and internal standard were mixed in a 1:1:1 abundance ratio (total 6 triplex). 


\subsection{Peptide fractionation using strong cation exchange chromatography (SCX)}

The dimethyl-labeled peptides were spin-dried and subsequently reconstituted in $500 \mu \mathrm{l}$ solvent A (30\% ACN (v/v), 0.5\% formic acid (v/v), pH 3). SCX was performed at $200 \mu \mathrm{l} / \mathrm{min}$ using Zorbax BioSCX-Series II columns (0.8-mm inner diameter x 50-mm length; $3.5 \mathrm{~mm}$ particle size) and a Famos autosampler (LC Packings). After sample loading, the first 20 min were run isocratically at $100 \%$ solvent $\mathrm{A}$, followed by an increasing $\mathrm{pH}$ gradient using solvent B (30\% ACN (v/v), 0.5\% formic acid (v/v), $540 \mathrm{mM}$ ammonium formate, $\mathrm{pH} 5)$. SCX fractions were automatically collected using an on-line Probot system (LC Packings).

2.6 Enrichment of phosphopeptides using immobilized metal ion affinity chromatography (IMAC)

SCX fractions were spin-dried and resuspended in $300 \mu$ l solvent C ( $250 \mathrm{mM}$ acetic acid, 30\% ACN (v/v)). Peptides were gently mixed with $80 \mu$ l Phos-Select iron affinity gel (SigmaAldrich) and incubated at room temperature for $1.5 \mathrm{~h}$ using a tube rotator. The mixture was transferred into SigmaPrep spin columns (Sigma-Aldrich) and rinsed twice with $200 \mu \mathrm{l}$ solvent $C$, then with $200 \mu$ double distilled water. The bound phosphopeptides were eluted with $60 \mu$ l solvent $\mathrm{D}\left(400 \mathrm{mM} \mathrm{NH}_{4} \mathrm{OH}, 30 \% \mathrm{ACN}\right)$ by centrifugation at $8200 \mathrm{~g}$. Eluted phosphopeptides were spin-dried and kept at $-20{ }^{\circ} \mathrm{C}$ until LC-MS/MS analysis.

\subsection{LC-MS/MS analysis}

On-line liquid chromatography was performed on a NanoLC-Ultra system (Eksigent). A $4 \mu \mathrm{l}$ sample was loaded at $7.5 \mu \mathrm{min}^{-1}$ on a precolumn cartridge (stationary phase: Biosphère C18, particles of $5 \mu \mathrm{m}$; column: 360/100 $\mu \mathrm{m}$ i.d., $2 \mathrm{~cm}$ length; Nanoseparations) and desalted with $0.1 \%$ formic acid in water. After $3 \mathrm{~min}$, the precolumn cartridge was connected to the separating Biosphère $\mathrm{C} 18$ column (stationary phase: Biosphère $\mathrm{C} 18$, particles of $3 \mu \mathrm{m}$; column $360 / 75 \mu \mathrm{m}$ i.d., $30 \mathrm{~cm}$ length; Nanoseparations). Buffers were $0.1 \%$ formic acid in water (solvent E) and $0.1 \%$ formic acid in ACN (solvent F). Peptide separation was achieved using a linear gradient from 5 to $95 \%$ of solvent $\mathrm{F}$ at $300 \mathrm{nl} \mathrm{min}{ }^{-1}$. Eluted peptides were analyzed with a Q-Exactive mass spectrometer (Thermo Scientific) using a nano-electrospray 
interface. Ionisation was performed with liquid junction and an uncoated capillary probe (10 $\mu \mathrm{m}$ i.d.; New Objective). Peptide ions were analyzed using XCalibur 2.3 with the following data-dependent acquisition steps: (1) full MS scan on a 400 to 1400 range of mass-to-charge ratio $(\mathrm{m} / \mathrm{z})$ with a resolution of 70000 and (2) MS/MS (normalized collision energy: $27 \%$; resolution: 17500). Step 2 was repeated for the 8 major ions detected in step 1. Dynamic exclusion was set to $40 \mathrm{~s}$.

\subsection{Identification of peptides and phosphorylation sites}

Database searches were performed using X!Tandem Alanine (http://www.thegpm.org/TANDEM). Cys carboxyamidomethylation and light, intermediate and heavy dimethylation of peptide $\mathrm{N}$-termini and lysine residues were set as static modifications while Met oxidation and phosphorylation of tyrosine, serine or threonine residues were set as variable modifications. Precursor mass tolerance was $10 \mathrm{ppm}$ and fragment mass tolerance was $0.02 \mathrm{Da}$. Identifications were performed using the TAIR 10 database (http://www.arabidopsis.org/). Identified proteins were filtered and grouped using the X!Tandem pipeline C++ v0.2.37 (http://pappso.inra.fr/bioinfo/xtandempipeline/). Data filtering was achieved according to a peptide E value smaller than 0.001 . The false discovery rate (FDR) was estimated to $0.07 \%$ on peptide and $1.19 \%$ on protein.

\subsection{Quantification of phosphopeptides}

Relative quantification of phosphopeptides was performed using the MassChroQ software [42] by extracting ion chromatograms (XICS) of all identified phosphopeptides within a 10 ppm window and by integrating the area of the XIC peak at their corresponding retention time. LC-MS/MS chromatogram alignment was performed by using common MS/MS identifications as landmarks to evaluate retention time deviations along the chromatographic profiles. Alignments were performed within groups of LC-MS/MS runs originating from similar SCX fractions. For each peptide detected in the heavy and light or intermediate and light form in a single LC-MS/MS run, a light-to-heavy or light-tointermediate ratio was computed. To compensate for possible global deviations between LC- 
MS/MS runs, normalization was performed by centering to 1 the distribution of all ratios within each LC-MS/MS run. Subsequent statistical analyses were performed on $\log _{10^{-}}$ transformed normalized data. We carried out a two-way ANOVA analysis with $p$ value $=0.01$ to identify differentially abundant phosphopeptides between samples, followed by the posthoc analysis Tukey's test to identify the phosphopeptides statistically more abundant in CPK5ac-WT samples compared to CPK5ac-dead samples. All mass spectrometry proteomics and phosphoproteomics data have been deposited to the ProteomeXchange Consortium (http://proteomecentral.proteomexchange.org) via the PRIDE partner repository [43] with the dataset identifier PXD028256.

\subsection{Production of recombinant proteins}

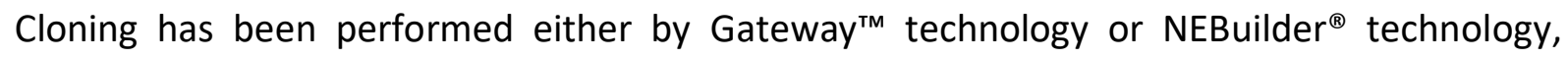
using the coding sequence of candidate genes (either full-length or truncated forms) amplified with primers listed in Supplementary Table S1. For the Gateway ${ }^{\mathrm{TM}}$ cloning, the PCR product was cloned into the Gateway ${ }^{\mathrm{TM}}$ entry vector pDONR207 (Invitrogen). The genes were then shuttled by Gateway ${ }^{\mathrm{TM}}$ LR Clonase reaction (Invitrogen) into pGEX-3X or pDEST-6HisMBP (Addgene) allowing a GST or a 6His-MBP (6 histidine-maltose binding protein) fusion at the N-terminus, respectively. For the NEBuilder ${ }^{\circledR}$ cloning, the PCR product was cloned into pGEX-2T (GE Healthcare) by recombination using NEBuilder ${ }^{\circledR} \mathrm{HiFi}$ DNA Assembly Master Mix (New England Biolabs). The construct pGEX-2T-CPK5 was previously reported [37]. Protein expression was induced in Escherichia coli BL21(DE3)pLys cells (Stratagene) with $0.2 \mathrm{mM}$ IPTG (isopropyl $\beta$-D-thiogalactopyranoside) at $18^{\circ} \mathrm{C}$ for $16 \mathrm{~h}$. GST-fused proteins were purified as previously described [37]. 6His-MBP fused proteins were purified using Ni-TED columns (Macherey Nagel) according to manufacturer's instructions. Eluted fractions were

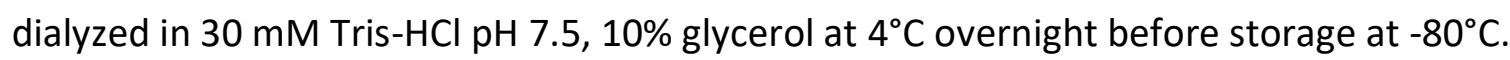

\subsection{Immunoprecipitation and in vitro kinase assays}

Ten-day-old seedlings were ground in liquid nitrogen and homogenized in immunoprecipitation buffer ( $50 \mathrm{mM}$ Tris- $\mathrm{HCl}$ pH 7.5, 5 mM EDTA, 5 mM EGTA, $50 \mathrm{mM} \beta$ - 
glycerophosphate, $10 \mathrm{mM}$ sodium fluoride, $1 \mathrm{mM}$ orthovanadate, $2 \mathrm{mM}$ DTT, $1 \mathrm{X}$ antiprotease cocktail (Roche), $150 \mathrm{mM} \mathrm{NaCl}, 1 \%$ Triton X-100) before centrifugation at $21100 \mathrm{~g}$ for $15 \mathrm{~min}$ at $4^{\circ} \mathrm{C}$. Protein concentration was determined with Bradford method. Protein extract (100-300 $\mu \mathrm{g})$ was incubated with $1 \mu \mathrm{l}$ polyclonal anti-HA antibody (Sigma) in immunoprecipitation buffer for $2 \mathrm{~h} 30$ at $4^{\circ} \mathrm{C}$. Then, $20 \mu \mathrm{l}$ of $50 \%$ slurry Protein A-sepharose beads were added and the incubation was continued for another $1 \mathrm{~h}$. The immunoprecipitates were washed three times in immunoprecipitation buffer and twice in protein kinase buffer (20 mM Tris- $\mathrm{HCl}$ pH 7.5, $0.5 \mathrm{mM} \mathrm{EGTA,} 10 \mathrm{mM} \mathrm{MgCl}, 1 \mathrm{mM}$ DTT). Then, the immunoprecipitates were incubated in reaction buffer $(20 \mathrm{mM}$ Tris- $\mathrm{HCl}$ pH 7.5, 5 mM EGTA or $1 \mathrm{mM} \mathrm{CaCl}_{2}, 10 \mathrm{mM} \mathrm{MgCl} 2,1 \mathrm{mM}$ DTT, $50 \mu \mathrm{M}$ cold ATP, $2 \mu \mathrm{Ci}$ [ $\gamma^{-}{ }^{33} \mathrm{P}$ ]ATP) with the substrate (either 1-2 $\mu \mathrm{g}$ purified recombinant protein or histone $\mathrm{H3}$ ), at room temperature for $30 \mathrm{~min}$. The reaction was stopped by adding SDS-PAGE loading buffer. Samples were heated at $95^{\circ} \mathrm{C}$ for $3 \mathrm{~min}$ and separated on SDS-PAGE. Phosphorylation was detected on dried gels by the Typhoon imaging system (GE Healthcare).

\subsection{Western-blot analysis}

Total protein extracts $(20-30 \mu \mathrm{g})$ were separated on $10 \%$ SDS-polyacrylamide gels and immunoblotted onto polyvinylidene difluoride membranes (Millipore). Blots were blocked with 5\% (w/v) defatted milk in TBS-T (10 mM Tris- $\mathrm{HCl}, \mathrm{pH} 7.5,154 \mathrm{mM} \mathrm{NaCl}, 0.1 \%(\mathrm{v} / \mathrm{v})$ Tween 20) and probed with 1:10000 monoclonal anti-HA antibodies (Roche). Horseradish peroxidase-conjugated anti-rat IgG (Sigma) were used as secondary antibodies and the reactions were visualized using Clarity enhanced chemiluminescence ECL kit (BioRad).

\subsection{Mass spectrometry analysis of in vitro phosphorylation assays}

Purified recombinant proteins and GST-CPK5FL [37] were mixed together in kinase reaction buffer (20 mM Tris- $\mathrm{HCl}$ pH 7.5, $10 \mathrm{mM} \mathrm{MgCl}, 1 \mathrm{mM} \mathrm{CaCl}_{2}, 1 \mathrm{mM}$ DTT and $50 \mu \mathrm{M}$ ATP) and incubated at room temperature for $30 \mathrm{~min}$. The reaction was stopped by adding SDS-PAGE loading buffer. Samples were heated at $95^{\circ} \mathrm{C}$ for $3 \mathrm{~min}$ and separated on SDS-PAGE. Gels 
were stained with coomassie brilliant blue and the band corresponding to the protein of interest was excised out and analyzed as previously described [30].

\subsection{Bimolecular Fluorescence Complementation (BiFC)}

The BiFC constructs were generated by Gateway ${ }^{\mathrm{TM}}$ LR Clonase reaction (Invitrogen) between the pDONR207 entry clones of full-length proteins (see section 2.10) and the pBiFP vectors [44]: CPK5 was cloned into pBiFP-4, ATL6/ATL31 into pBiFP-1, DRP2B/EiF4G/TSR1-like into pBiFP-2. For CPK5, prior to LR reaction, the pDONR207 construct was mutated using the primers listed in Supplementary Table S2 to delete the stop codon and allow C-terminal fusion. For ATL6/ATL31, the pDONR207 construct generated without the stop codon was used for the LR reaction. Globosa-pBiFP-2 and Deficiencs-pBiFP-3 were previously reported [44]. The BiFC constructs were introduced by heat shock in thermocompetent $A$. tumefaciens GV3101 strain. 4-week-old Nicotiana benthamiana plants were transiently transformed by syringe infiltration with fresh cultures of $A$. tumefaciens washed and resuspended in transformation buffer (25 mM D-glucose, $50 \mathrm{mM}$ MES, $2 \mathrm{mM} \mathrm{Na}_{3} \mathrm{PO}_{4}, 100 \mu \mathrm{M}$ acetosyringone). For each infiltration, the two constructions to test were mixed at $O D=0.3$, in presence of the viral suppressor of RNA silencing HC-Pro (OD=0.15). The YFP fluorescence was observed two days post infiltration, using a Zeiss LSM880 confocal microscope, with a Plan-Apochromat 40x/1.3 oil DIC M27 objective, an Ar laser excitation wavelength of 514 $\mathrm{nm}$, and a detection spectrum between $517 \mathrm{~nm}$ and $579 \mathrm{~nm}$. Images were prepared with the Zen 2.3 lite software.

\subsection{Quantitative real-time PCR}

Total RNA was isolated from 10-day-old seedlings using the NucleoSpin ${ }^{\circledR}$ RNA plus kit (Macherey-Nagel). cDNA was synthesized from $3 \mu \mathrm{g}$ of total RNA using $0.5 \mu \mathrm{g}$ of oligo(dT) primer and SuperScript II reverse transcriptase (Invitrogen). The qRT-PCR analysis was carried out with a CFX384 Touch $^{\text {TM }}$ real-time PCR system (Bio-Rad) using SYBR ${ }^{\circledR}$ Premix Ex Taq $^{\text {TM }}$ (Tli RNase H Plus) (Takara). TUB4 (tubulin $\beta$-chain 4; At5g44340) and EIF4a (eukaryotic translation initiation factor 4A; At3g13920) were used as control genes. To distinguish 
CPK5FL and CPK5ac expression, we designed primers in the $3^{\prime}$ end of CPK5FL: CPK5-3'-For TATGGATGCGGCTGATGTAG and CPK5-3'-Rev GCTCTTCCCGCTCTAGTTTG. All other primers used for qRT-PCR have been described previously [13]. A nonparametric multiple comparison statistical test with Tukey contrast was performed with the R package nparcomp to identify statistical differences between samples.

\subsection{Trypan blue staining}

Leaf punches of 4-week-old plants were equilibrated in $\mathrm{H}_{2} \mathrm{O}$ overnight prior to $1 \mu \mathrm{M}$ Dex or mock ( $0.05 \%$ final ethanol) treatment for $48 \mathrm{~h}$. Leaf punches were boiled for $1 \mathrm{~min}$ in trypan blue solution (3.3 $\mathrm{mg} \mathrm{mL}^{-1}$ trypan blue, 33.3\% acetic acid, $33.3 \%$ phenol, $33.3 \%$ glycerol) diluted in 1 volume of $100 \%$ ethanol. Then punches were bleached in $2.5 \mathrm{~g} \mathrm{~mL}^{-1}$ choral hydrate and conserved in $50 \%$ glycerol. Leaf staining was observed on a Leica MZ16F binocular loupe.

\section{Results}

\subsection{Induction of constitutively active AtCPK5 triggers immune responses}

In order to identify in vivo substrates of AtCPK5 (named CPK5 hereafter), we generated Arabidopsis transgenic lines expressing the truncated constitutively active form of CPK5 (CPK5ac-WT) tagged with an HA epitope, under the control of a dexamethasone (Dex)inducible promoter. Transgenic line expressing the truncated variant mutated in the kinase domain (Asp 221 into alanine, CPK5ac-dead) was used as a negative control. The transgene expression was monitored at the protein level by western-blot with anti-HA antibody (Fig. 1A) and at the transcript level by qRT-PCR (Fig. 1B). Based on comparable expression level, we selected three independent lines for the WT variant and one line for the dead variant. We also analyzed CPK5ac-HA activity on the generic substrate histone, after immunoprecipitation with anti-HA antibody (Fig. 1A). Importantly, CPK5ac expression was detected only upon Dex treatment and CPK5ac activity was observed exclusively with the WT variant despite a strong expression of the dead variant (Fig. 1). Moreover, the Dex 
induction of CPK5ac did not affect the expression of endogenous CPK5 (Fig. 1B), indicating that the subsequent phenotypes observed are due to CPK5ac expression.

CPK5 has been identified as a positive regulator of cell death and defense gene expression $[13,14,18,23,45]$. To validate the CPK5ac-Dex-inducible lines at the physiological level, we monitored cell death on leaf punches treated with mock or Dex for $48 \mathrm{~h}$ (Fig. 2A). While Dex induction triggered cell death in the three Dex:CPK5ac-WT lines, no staining could be observed in the Dex:CPK5ac-dead line, despite a comparable protein amount (Fig. 2A, 2B). Similarly, the expression of CPK5 target genes NHL10, WAK2, CYP81F2 and FOX [13] was exclusively induced in Dex:CPK5ac-WT lines upon Dex application (Fig. 2C, Supplementary Fig. 1). Taken together, these results indicate that CPK5ac expressed in Dex-inducible lines is functional in planta and thus able to phosphorylate endogenous substrates.

\subsection{Phosphoproteomic identification of AtCPK5 substrates}

We first carried out a kinetics of Dex treatment up to $6 \mathrm{~h}$ and analyzed CPK5ac expression and activity after immunoprecipitation with anti-HA antibody (Fig. 3A). While kinase activity of CPK5ac-WT was detected from $2 \mathrm{~h}$ of Dex application, the protein clearly accumulated after $4 \mathrm{~h}$. We thus selected $2 \mathrm{~h}$ and $4 \mathrm{~h}$ time points for the phosphoproteomic analysis, in order to limit dephosphorylation and secondary phosphorylation events that could occur at later time points. To avoid potential bias induced by the position of the T-DNA insertion, we performed each independent biological replicate with one of the three CPK5ac-WT lines. The proteome analysis of the three replicates did not reveal any significant modification among samples except the accumulation of CPK5ac-HA after $4 \mathrm{~h}$, as observed in the control western-blot (Supplementary Table S3, Supplementary Fig. 2, Fig. 3A). This suggests that, in our conditions, Dex treatment did not trigger any major side effect. By contrast, the phosphoproteome analysis (Fig. 3B, Supplementary Table S4) retrieved five phosphopeptides, corresponding to five proteins, which were significantly more abundant in CPK5ac-WT lines compared to the CPK5ac-dead line ( $p<0.05$, between 1.2- to 2.5-fold change): the dynamin-related protein 2B DRP2B (also called Arabidopsis dynamin-like 3 ADL3), the eukaryotic translation initiation factor 4G EiF4G (also called Cucumovirus multiplication 2 CUM2), the pre-rRNA-processing TSR1-like protein and the two Ring-H2 type 
E3 ubiquitin ligase Arabidopsis toxicos en levadura 6 and 31 ATL6 and ATL31 (Fig. 4, Table 1). Importantly, four other phosphopeptides from three of these candidates (DRP2B, EiF4G and ATL6) were not significantly affected in the various samples, and two of the proteins (DRP2B and EiF4G) were quantified in the proteome but did not show any significant variation (Supplementary Fig. 3). This suggests that the accumulation observed of the five phosphopeptides in the CPK5ac-WT lines is specific and results from the activity of CPK5acWT. Interestingly, three of the identified phosphosites do not match the minimal CDPK motifs R/K-X-X-S/T or S/T-X-R/K [46] (Table 1). This suggests that either, the candidates are not direct targets of CPK5, or the CDPK motifs are less conserved than previously thought.

\subsection{Validation of the candidates}

In order to test whether the candidates are direct target of CPK5, we carried out in vitro phosphorylation assays using recombinant protein produced in bacteria as substrates. We could produce the GST-DRP2B fusion but failed with other candidates. Since EiF4G and TSR1like are quite big proteins, we decided to clone truncated versions including the identified phosphosites (EiF4G C-terminus aa 916-1727 and TSR1-like N-terminus aa 1-485) and succeeded in purifying the GST fusions. For ATL6 and ATL31, we could produce a 6His-MBP fusion at the N-terminus. CPK5 was immunopurified from 35S-CPK5-HA seedlings with an anti-HA antibody and the kinase activity was monitored in vitro in the presence and absence of calcium. Interestingly, the 5 substrates were phosphorylated in vitro by CPK5-HA in a calcium-dependent manner (Fig. 5). No phosphosignal was detected from WT plants, demonstrating the specificity of CPK5-HA immunoprecipitation, as suggested by the western-blot. Finally, the GST and His-MBP tags used as negative controls were not phosphorylated by CPK5-HA, demonstrating that the 5 candidates are direct targets of CPK5 in vitro.

To go further, we investigated the in vivo interaction between CPK5 and the candidates using bimolecular fluorescence complementation (BiFC). CPK5 was fused to the half C-terminal part of YFP while the full-length candidates were fused to the YFP half $\mathrm{N}$-terminal part. Both proteins were transiently co-expressed in tobacco leaves and fluorescence was detected by confocal microscopy. Interestingly, different interaction patterns were observed (Fig. 6), 
consistent with the ubiquitous localization of CPK5 in cytosol, nucleus and membranes $[13,37,47]$. In particular, CPK5 was recently identified in a nuclear proteome [48] and was shown to translocate to the nucleus when co-expressed with AvrRpt2, which was required for its role in transcriptional regulation $[14,15]$. CPK5 interacted with EiF4G in the cytosol while the interaction with TSR1-like occurred exclusively in the nucleus. CPK5 interacted with DRP2B in both cytosol and plasma membrane with some punctate signals detected in membrane (Supplementary Fig. 4), reminiscent of NtDRP2 localization in small vesicle-like structures [49]. Negative controls with Deficiens and Globosa, which interacted together in the cytosol and nucleus [44] but with none of the candidates, validated the specificity of the observed interactions. However, we could not detect any interaction between CPK5 and ATL6/ATL31, potentially for technical reasons, either because of low expression of ATL proteins and/or conformational limitations with half-YFP fusions. Indeed, ATL31-nYFP was hardly detectable by western-blot unlike ATL6-nYFP and CPK5-cYFP (Supplementary Fig. 5). We thus focused on ATL31 to further validate the targeted phosphosites. We carried out an in vitro kinase assay with recombinant GST-CPK5 and HisMBP-ATL31, in the presence of calcium, and analyzed the reaction by mass spectrometry (Fig. 7A,B). Despite a low coverage of the protein (12\%), we could not only confirm the S245 phosphosite identified in vivo but also revealed an additional target $\mathrm{S} 280$. We mutated both sites individually or simultaneously into alanine to block phosphorylation, in the ATL31 recombinant protein, and performed an in vitro kinase assay with CPK5 immunoprecipitated from 35S-CPK5-HA seedlings (Fig. 7C). Both single mutations reduced the phosphorylation of ATL31 by CPK5, confirming that both sites are direct targets of CPK5. Moreover, the double mutant ATL31 ${ }^{\text {S245A-S280A }}$ displayed similar phosphorylation level as the single phosphoablative mutant $\mathrm{ATL} 31^{\mathrm{S} 280 \mathrm{~A}}$, suggesting that $\mathrm{S} 280$ is the major CPK5 target site in vitro.

\subsection{Discussion}

Calcium signaling is a critical component of plant signal transduction, and relies on various types of calcium decoders. The CDPKs represent one of the major calcium sensor families that are involved in plant development and stress responses to biotic and abiotic stimuli [12]. Among them, AtCPK5 has been reported as a positive regulator of pathogen-associated 
molecular pattern (PAMP)-triggered immunity (PTI) and effector-triggered immunity (ETI) $[13,14,17-20,23,45]$, through the regulation of oxidative burst, gene expression, cell death and hormone signaling but the underlying molecular mechanisms still remain mostly unknown. Here, we proposed to identify in vivo substrates of AtCPK5 to decipher its functions in planta.

\subsection{Substrate identification by a phosphoproteomic approach}

To mimic the stress activation of AtCPK5, we generated transgenic lines expressing a constitutively active form of AtCPK5 under the control of a Dex inducible promoter (Fig. 1). The induction of AtCPK5-dependent defense responses upon Dex treatment demonstrated the in vivo functionality of the system (Fig. 2). The phosphoproteome analysis of those lines revealed five new putative substrates of AtCPK5 that were all confirmed as in vitro targets of AtCPK5 (Fig. 3, 4, 5). Unfortunately, none of the known AtCPK5 substrates, except RBOHD, could be retrieved, probably due to different experimental conditions. For example, WRKY8/28/33 identified as AtCPK5 substrates during plant immunity [14,23] are not well expressed in seedlings [50], which were used in the present study. Nonetheless, among the 6 phosphopeptides identified for RBOHD, one contained an AtCPK5 target site, S163 [18,22]. Although the difference was not statistical, the S163-phosphopeptide displayed a tendency to accumulate in CPK5ac-WT lines compared to the CPK5ac-dead line, after $4 \mathrm{~h}$ (Supplementary Fig. 6). Considering that four of the five phospho-candidates accumulated only after $4 \mathrm{~h}$, a longer Dex treatment could have increased the differential phosphorylation of substrates, including RBOHD. Indeed, putative substrates of AtMPK3 and AtMPK6 were identified by the Dex induction of constitutively active NtMEKK $2^{\text {DD }}$ for $6 \mathrm{~h}$ [33]. However, in a recent study, the in vivo phosphorylation of ORE1 by AtCPK1 was only detected transiently 1 $\mathrm{h}$ after the induction of the AtCPK1 active form [36]. Those data indicate that different experimental designs are likely to reveal different substrates. Importantly, three of the identified phosphosites (DRP2B S844, EIF4G S1525 and ATL31 S280) have been reported as differentially phosphorylated upon various stimuli such as flg22, cold, drought, $A B A, \mathrm{H}_{2} \mathrm{O}_{2}$ or salt stress $[26,32,51,52]$, suggesting some biological relevance. The potential function of 
AtCPK5 in regulating DRP2B, EIF4G and ATL31 in those biological contexts require further investigation.

\subsection{New phospho-motifs of CDPKs}

Determining protein kinase recognition motif is very helpful to identify protein kinases involved in a given cellular process, by scanning phosphoproteome data with specific phosphomotifs [53]. While some protein kinases seem to display strong specificities like MAPKs that target S/T-P motifs, CDPKs seemed to be less stringent with at least 4 characterized motifs, which include a basic residue either in position $-3,+2$ or $+3 /+4[46]$. Interestingly, three of the phosphosites identified in this study do not match any known CDPK motif, suggesting that the recognition motif of CDPK is even more diverse than anticipated (Table 1). In this respect, it is worth noting that three recent studies demonstrated a functional role for the phosphosite targeted by a CDPK which did not match CDPK motif. Firstly, AtCPK4 phosphorylates the guanine nucleotide exchange factor RopGEF1 at multiple sites in vitro, including the non-consensus CDPK site S51, whose phosphorylation in vivo triggers RopGEF1 degradation and subsequent release of RopGEF1-mediated inhibition of root hair development [54]. Secondly, AtCPK5 and AtCPK6 phosphorylate the transcription factor WRKY33 on the CDPK-unrelated phosphosite T229, increasing WRKY33 DNA binding and leading to camalexin production upon fungal infection [23]. Thirdly, AtCPK5 phosphorylates in vitro the chitin receptor LYK5 on non-consensus CDPK sites S323 and S542, whose phosphoablative variants S323A and S542A cannot complement the lyk5 mutant for chitin-activation of MAPKs [55]. Thus, the CDPK motifs would deserve a bioinformatic reevaluation to limit the underestimation of putative CDPK targets in high throughput phosphoproteome analyses.

\subsection{Putative novel functions of CPK5 in plant immunity}

AtCPK5 has been characterized as a positive regulator of bacterial and fungal resistance in both PTI and ETI responses. Besides the activation of RBOHD to induce oxidative burst $[16,18]$, AtCPK5 has mainly been involved in transcriptional regulation, partly through WRKY 
phosphorylation, to trigger the biosynthesis of SA, ethylene or camalexin $[13,14,20,21,23,45,56]$. The identification of four new putative substrates involved in plant immunity provides additional hints for AtCPK5 functions in plant defense. DRP2B is a bona fide ortholog of mammalian dynamins which are involved in clathrin-coated vesicles trafficking [57]. In particular, flg22-induced FLS2 internalization, which is required for appropriate flg22 signaling, was reduced in Arabidopsis drp $2 b$ mutant and in tobacco leaves silenced for DRP2B homologs [49,58]. Moreover, $d r p 2 b$ mutant was more susceptible to Pseudomonas syringae [58], and the phosphorylation of S844 targeted by AtCPK5 increased upon flg22 perception [51]. It is thus tempting to speculate that AtCPK5 regulates FLS2 internalization through the phosphorylation of DRP2B. However, $d r p 2 b$ mutant also exhibited increased flg22 responses including $\mathrm{Ca}^{2+}$ influx, oxidative burst and callose deposition, consistent with a negative role of DRP2B in flg22 signaling [58]. The connection between AtCPK5 and DRP2B in plant immunity is likely complex and will require further investigation.

ATL6 and ATL31 are closely-related RING-type E3 ubiquitin ligases that have been extensively studied in the context of $\mathrm{C} / \mathrm{N}$-nutrient response. Both proteins were shown to promote growth under high $\mathrm{C} / \mathrm{N}$ ratio, by triggering the degradation of $14-3-3$ proteins $[59,60]$. Moreover, this function was dependent on the phosphorylation of a conserved site, T240 in ATL6 and T209 in ATL31, by Feronia and CIPKs, respectively [61,62]. Interestingly, those sites are different from the ones targeted by AtCPK5, especially S280 whose phosphorylation increased upon flg22 treatment [26]. This raises the attractive hypothesis that a specific phosphocode of ATL6 and ATL31 regulated by multiple protein kinases mediate differential functions of ATLs in development and stress responses.

Finally, AtCPK5 might be involved in defense against some viruses because the knockout mutant of EiF4G exhibited differential phenotypes upon viral infection: eif4g was susceptible to plum pox virus, turnip mosaic virus and lettuce mosaic virus like wild type plants but resistant to clover yellow vein virus, cucumber mosaic virus and turnip crinkle virus $[63,64]$. This hypothesis is especially interesting considering that only 2 CDPKs have been reported so far in viral infection, either as a promoting factor for viral replication $[65,66]$ or blocking viral cell-to-cell propagation [67]. Further studies will be required to explore the CPK5 regulation of the newly identified putative substrates. 


\section{Funding}

This work was supported by the Agence Nationale de la Recherche to M.B. (ANR-15-CE200003-01) and the Ministère de l'Enseignement Supérieur et de la Recherche to T.Y.D. (MERS, doctoral grant). The IPS2 benefits from the support of the LabEx Saclay Plant Sciences-SPS (ANR-10-LABX-0040-SPS).

\section{Authors contributions}

M.B. designed the study. M.B, M.Z, H.H. and J.C. supervised the experiments. T.Y.D., L.A.O., M.D., J.L., N.V., N.R. and M.B. performed the experiments. T.Y.D., L.A.O., M.D., M.Z., J.L., N.R. and M.B. analyzed the data. MB wrote the manuscript with the contribution of all coauthors.

Declaration of Competing Interest

The authors declared no conflict of interest.

Appendix A. Supplementary data

Supplementary Figure 1. Induction of CPK5 target genes in transgenic Dex:CPK5ac lines.

Supplementary Figure 2. Quantification of the only protein specifically accumulated upon Dex treatment in Dex lines.

Supplementary Figure 3. Quantification of phosphopeptides and proteins not altered in Dex:CPK5ac-HA WT and dead lines, among the 5 substrate candidates.

Supplementary Figure 4. DRP2B and CPK5 interact in vivo in plasma membrane and vesiclelike structures.

Supplementary Figure 5. Expression of ATL6/31-nYFP and CPK5-cYFP in tobacco leaves. 
Supplementary Figure 6. Quantification of the S163-containing phosphopeptide of RBOHD in Dex:CPK5ac-HA WT and dead lines.

Supplementary Table S1. Sequence of primers used for cloning.

Supplementary Table S2. Sequence of primers used for mutagenesis.

Supplementary Table S3. Proteome data of Dex:CPK5ac-HA WT and Dex:CPK5ac-HA dead lines.

Supplementary Table S4. Phosphoproteome data of Dex:CPK5ac-HA WT and Dex:CPK5ac-HA dead lines.

References

[1] P.J. White, M.R. Broadley, Calcium in plants., Ann. Bot. 92 (2003) 487-511.

[2] A.N. Dodd, J. Kudla, D. Sanders, The language of calcium signaling, Annu. Rev. Plant Biol. 61 (2010) 593-620.

[3] J. Kudla, D. Becker, E. Grill, R. Hedrich, M. Hippler, U. Kummer, M. Parniske, T. Romeis, K. Schumacher, Advances and current challenges in calcium signaling, New Phytol. 218 (2018) 414-431.

[4] J. Liu, G. Lenzoni, M.R. Knight, Design principle for decoding calcium signals to generate specific gene expression via transcription, Plant Physiol. 182 (2020) 17431761.

[5] M. Boudsocq, J. Sheen, Stress signaling II: calcium sensing and signaling, in: Abiotic Stress Adapt. Plants, 2010: pp. 75-90.

[6] K.H. Edel, E. Marchadier, C. Brownlee, J. Kudla, A.M. Hetherington, The evolution of calcium-based signalling in plants, Curr. Biol. 27 (2017) R667-R679.

[7] A. Liese, T. Romeis, Biochemical regulation of in vivo function of plant calciumdependent protein kinases (CDPK), Biochim. Biophys. Acta - Mol. Cell Res. 1833 (2013) 1582-1589. 
[8] M. Boudsocq, J. Sheen, CDPKs in immune and stress signaling., Trends Plant Sci. 18 (2013) 30-40.

[9] J.F. Harper, J.F. Huang, S.J. Lloyd, Genetic identification of an autoinhibitor in CDPK, a protein kinase with a calmodulin-like domain, Biochemistry. 33 (1994) 7267-7277.

[10] A.C. Harmon, B. Yoo, C. Mccaffery, Pseudosubstrate inhibition of CDPK, a protein kinase with a calmodulin-like domain, Biochemistry. 33 (1994) 7278-7287.

[11] A.K. Wernimont, J.D. Artz, P. Finerty Jr., Y.H. Lin, M. Amani, A. Allali-Hassani, G. Senisterra, M. Vedadi, W. Tempel, F. Mackenzie, I. Chau, S. Lourido, L.D. Sibley, R. Hui, Structures of apicomplexan calcium-dependent protein kinases reveal mechanism of activation by calcium, Nat. Struct. Mol. Biol. 17 (2010) 596-601.

[12] T. Yip Delormel, M. Boudsocq, Properties and functions of calcium-dependent protein kinases and their relatives in Arabidopsis thaliana, New Phytol. 224 (2019) 585-604.

[13] M. Boudsocq, M.R. Willmann, M. McCormack, H. Lee, L. Shan, P. He, J. Bush, S.-H. Cheng, J. Sheen, Differential innate immune signalling via $\mathrm{Ca}^{2+}$ sensor protein kinases., Nature. 464 (2010) 418-422.

[14] X. Gao, X. Chen, W. Lin, S. Chen, D. Lu, Y. Niu, L. Li, C. Cheng, M. McCormack, J. Sheen, L. Shan, P. He, Bifurcation of Arabidopsis NLR immune signaling via $\mathrm{Ca}^{2+}$-dependent protein kinases., PLoS Pathog. 9 (2013) e1003127.

[15] X. Gao, P. He, Nuclear dynamics of Arabidopsis calcium-dependent protein kinases in effector-triggered immunity, Plant Signal. Behav. 8 (2013) e23868.

[16] X. Luo, N. Xu, J. Huang, F. Gao, H. Zou, M. Boudsocq, G.L. Coaker, J. Liu, A lectin receptor-like kinase mediates pattern-triggered salicylic acid signaling, Plant Physiol. 174 (2017) 2501-2514.

[17] Y. Ma, Y. Zhao, R.K. Walker, G.A. Berkowitz, Molecular steps in the immune signaling pathway evoked by plant elicitor peptides: $\mathrm{Ca}^{2+}$-dependent protein kinases, nitric oxide, and reactive oxygen species are downstream from the early $\mathrm{Ca}^{2+}$ signal, Plant Physiol. 163 (2013) 1459-1471. 
[18] U. Dubiella, H. Seybold, G. Durian, E. Komander, R. Lassig, C.-P.P. Witte, W.X. Schulze, T. Romeis, Calcium-dependent protein kinase/NADPH oxidase activation circuit is required for rapid defense signal propagation, Proc. Natl. Acad. Sci. U. S. A. 110 (2013) 8744-8749.

[19] N. Liu, K. Hake, W. Wang, T. Zhao, T. Romeis, D. Tang, Calcium-dependent protein kinase 5 associates with the truncated NLR protein TIR-NBS2 to contribute to exo70B1mediated immunity, Plant Cell. 29 (2017) 746-759.

[20] M. Gravino, D.V. Savatin, A. MacOne, G. De Lorenzo, Ethylene production in Botrytis cinerea- and oligogalacturonide-induced immunity requires calcium-dependent protein kinases, Plant J. 84 (2015) 1073-1086.

[21] S. Li, X. Han, L. Yang, X. Deng, H. Wu, M. Zhang, Y. Liu, S. Zhang, J. Xu, Mitogenactivated protein kinases and calcium-dependent protein kinases are involved in wounding-induced ethylene biosynthesis in Arabidopsis thaliana, Plant. Cell Environ. 41 (2018) 134-147.

[22] Y. Kadota, J. Sklenar, P. Derbyshire, L. Stransfeld, S. Asai, V. Ntoukakis, J.D. Jones, K. Shirasu, F. Menke, A. Jones, C. Zipfel, Direct regulation of the NADPH oxidase RBOHD by the PRR-associated kinase BIK1 during plant immunity, Mol. Cell. 54 (2014) 43-55.

[23] J. Zhou, X. Wang, Y. He, T. Sang, P. Wang, S. Dai, S. Zhang, X. Meng, Differential phosphorylation of the transcription factor WRKY33 by the protein kinases CPK5/CPK6 and MPK3/MPK6 cooperatively regulates camalexin biosynthesis in Arabidopsis, Plant Cell. 32 (2020) 2621-2638.

[24] S.C. Popescu, G. V. Popescu, S. Bachan, Z. Zhang, M. Gerstein, M. Snyder, S.P. DineshKumar, MAPK target networks in Arabidopsis thaliana revealed using functional protein microarrays, Genes Dev. 23 (2009) 80-92.

[25] A. Curran, I.F. Chang, C.L. Chang, S. Garg, M.A. Rodriguez Milla, Y.D. Barron, Y. Li, S. Romanowsky, J.C. Cushman, M. Gribskov, A.C. Harmon, J.F. Harper, Calciumdependent protein kinases from Arabidopsis show substrate specificity differences in an analysis of 103 substrates, Front. Plant Sci. 2 (2011) 36. 
[26] P. Wang, C.C. Hsu, Y. Du, P. Zhu, C. Zhao, X. Fu, C. Zhang, J.S. Paez, A.P. Macho, W. Andy Tao, J.K. Zhu, Mapping proteome-wide targets of protein kinases in plant stress responses, Proc. Natl. Acad. Sci. U. S. A. 117 (2020) 3270-3280.

[27] Y. Uno, M.A. Rodriguez Milla, E. Maher, J.C. Cushman, Identification of proteins that interact with catalytically active calcium-dependent protein kinases from Arabidopsis, Mol. Genet. Genomics. 281 (2009) 375-390.

[28] S. Asai, T. Ichikawa, H. Nomura, M. Kobayashi, Y. Kamiyoshihara, H. Mori, Y. Kadota, C. Zipfel, J.D. Jones, H. Yoshioka, The variable domain of a plant calcium-dependent protein kinase (CDPK) confers subcellular localization and substrate recognition for NADPH oxidase, J. Biol. Chem. 288 (2013) 14332-14340.

[29] K.N. Swatek, R.S. Wilson, N. Ahsan, R.L. Tritz, J.J. Thelen, Multisite phosphorylation of 14-3-3 proteins by calcium-dependent protein kinases, Biochem. J. 459 (2014) 15-25.

[30] N. Rayapuram, J. Bigeard, H. Alhoraibi, L. Bonhomme, A.-M. Hesse, J. Vinh, H. Hirt, D. Pflieger, Quantitative phosphoproteomic analysis reveals shared and specific targets of Arabidopsis MPK3, MPK4 and MPK6, Mol. Cell. Proteomics. 17 (2018) 61-80.

[31] P. Wang, L. Xue, G. Batelli, S. Lee, Y.J. Hou, M.J. Van Oosten, H. Zhang, W.A. Tao, J.K. Zhu, Quantitative phosphoproteomics identifies SnRK2 protein kinase substrates and reveals the effectors of abscisic acid action, Proc. Natl. Acad. Sci. U. S. A. 110 (2013) 11205-11210.

[32] T. Umezawa, N. Sugiyama, F. Takahashi, J.C. Anderson, Y. Ishihama, S.C. Peck, K. Shinozaki, Genetics and phosphoproteomics reveal a protein phosphorylation network in the abscisic acid signaling pathway in arabidopsis thaliana, Sci. Signal. 6 (2013) rs8.

[33] W. Hoehenwarter, M. Thomas, E. Nukarinen, V. Egelhofer, H. Roehrig, W. Weckwerth, U. Conrath, G.J. Beckers, Tandem metal oxide affinity chromatography identifies novel in vivo MAP kinase substrates in Arabidopsis thaliana, Mol. Cell. Proteomics. 12 (2013) 369-380.

[34] T. Zhang, S. Chhajed, J.D. Schneider, G. Feng, W.-Y. Song, S. Chen, Proteomic 
characterization of MPK4 signaling network and putative substrates, Plant Mol. Biol. 101 (2019) 325-339.

[35] S. Berriri, A.V. Garcia, N. Frei dit Frey, W. Rozhon, S. Pateyron, N. Leonhardt, J.-L. Montillet, J. Leung, H. Hirt, J. Colcombet, Constitutively active mitogen-activated protein kinase versions reveal functions of Arabidopsis MPK4 in pathogen defense signaling., Plant Cell. 24 (2012) 4281-4293.

[36] G. Durian, M. Sedaghatmehr, L.P. Matallana-Ramirez, S.M. Schilling, S. Schaepe, T. Guerra, M. Herde, C.P. Witte, B. Mueller-Roeber, W.X. Schulze, S. Balazadeh, T. Romeis, Calcium-dependent protein kinase CPK1 controls cell death by in vivo phosphorylation of senescence master regulator ORE1, Plant Cell. 32 (2020) 16101625.

[37] M. Boudsocq, M.-J. Droillard, L. Regad, C. Laurière, Characterization of Arabidopsis calcium-dependent protein kinases: activated or not by calcium?, Biochem. J. 447 (2012) 291-299.

[38] M. Martinez-Trujillo, V. Limones-Briones, J.L. Cabrera-Ponce, L. Herrera-Estrella, Improving transformation efficiency of Arabidopsis thaliana by modifying the floral dip method, Plant Mol. Biol. Report. 22 (2004) 63-70.

[39] L. Bonhomme, B. Valot, F. Tardieu, M. Zivy, Phosphoproteome dynamics upon changes in plant water status reveal early events associated with rapid growth adjustment in maize leaves, Mol. Cell. Proteomics. 11 (2012) 957-972.

[40] M. Havé, T. Balliau, B. Cottyn-Boitte, E. Dérond, G. Cueff, F. Soulay, A. Lornac, P. Reichman, N. Dissmeyer, J.C. Avice, P. Gallois, L. Rajjou, M. Zivy, C. MasclauxDaubresse, Increases in activity of proteasome and papain-like cysteine protease in Arabidopsis autophagy mutants: Back-up compensatory effect or cell-death promoting effect?, J. Exp. Bot. 69 (2018) 1369-1385.

[41] P.J. Boersema, R. Raijmakers, S. Lemeer, S. Mohammed, A.J.R. Heck, Multiplex peptide stable isotope dimethyl labeling for quantitative proteomics, Nat. Protoc. 4 (2009) 484-494. 
[42] B. Valot, O. Langella, E. Nano, M. Zivy, MassChroQ: a versatile tool for mass spectrometry quantification, Proteomics. 11 (2011) 3572-3577.

[43] Y. Perez-Riverol, A. Csordas, J. Bai, M. Bernal-Llinares, S. Hewapathirana, D.J. Kundu, A. Inuganti, J. Griss, G. Mayer, M. Eisenacher, E. Pérez, J. Uszkoreit, J. Pfeuffer, T. Sachsenberg, Ş. Yilmaz, S. Tiwary, J. Cox, E. Audain, M. Walzer, A.F. Jarnuczak, T. Ternent, A. Brazma, J.A. Vizcaíno, The PRIDE database and related tools and resources in 2019: Improving support for quantification data, Nucleic Acids Res. 47 (2019) D442D450.

[44] J. Azimzadeh, P. Nacry, A. Christodoulidou, S. Drevensek, C. Camilleri, N. Amiour, F. Parcy, M. Pastuglia, D. Boucheza, Arabidopsis Tonneau1 proteins are essential for preprophase band formation and interact with centrin, Plant Cell. 20 (2008) 21462159.

[45] T. Guerra, S. Schilling, K. Hake, K. Gorzolka, F.P. Sylvester, B. Conrads, B. Westermann, T. Romeis, Calcium-dependent protein kinase 5 links calcium signaling with $\mathrm{N}$-hydroxyI-pipecolic acid- and SARD1-dependent immune memory in systemic acquired resistance, New Phytol. 225 (2020) 310-325.

[46] J.F. Harper, A. Harmon, Plants, symbiosis and parasites: a calcium signalling connection, Nat. Rev. Mol. Cell Biol. 6 (2005) 555-566.

[47] S.X. Lu, E.M. Hrabak, The myristoylated amino-terminus of an Arabidopsis calciumdependent protein kinase mediates plasma membrane localization, Plant Mol. Biol. 82 (2013) 267-278.

[48] C. Goto, S. Hashizume, Y. Fukao, I. Hara-Nishimura, K. Tamura, Comprehensive nuclear proteome of Arabidopsis obtained by sequential extraction, Nucleus. 10 (2019) 81-92.

[49] A. Chaparro-Garcia, S. Schwizer, J. Sklenar, K. Yoshida, B. Petre, J.I.B. Bos, S. Schornack, A.M.E. Jones, T.O. Bozkurt, S. Kamoun, Phytophthora infestans RXLR-WY effector AVR3a associates with dynamin-related protein 2 required for endocytosis of the plant pattern recognition receptor FLS2, PLoS One. 10 (2015) e0137071.

[50] J. Mergner, M. Frejno, M. List, M. Papacek, X. Chen, A. Chaudhary, P. Samaras, S. 
Richter, H. Shikata, M. Messerer, D. Lang, S. Altmann, P. Cyprys, D.P. Zolg, T. Mathieson, M. Bantscheff, T. Hofmann, S. Sprunck, P. Falter-braun, F. Johannes, Massspectrometry-based draft of the Arabidopsis proteome, Nature. 579 (2020) 409-414.

[51] T.S. Nühse, A.R. Bottrill, A.M.E. Jones, S.C. Peck, Quantitative phosphoproteomic analysis of plasma membrane proteins reveals regulatory mechanisms of plant innate immune responses, Plant J. 51 (2007) 931-940.

[52] J.J. Benschop, S. Mohammed, M. O’Flaherty, A.J. Heck, M. Slijper, F.L. Menke, Quantitative phosphoproteomics of early elicitor signaling in Arabidopsis, Mol. Cell. Proteomics. 6 (2007) 1198-1214.

[53] N. Rayapuram, L. Bonhomme, J. Bigeard, K. Haddadou, C. Przybylski, H. Hirt, D. Pflieger, Identification of novel PAMP-triggered phosphorylation and dephosphorylation events in Arabidopsis thaliana by quantitative phosphoproteomic analysis, J. Proteome Res. 13 (2014) 2137-2151.

[54] Z. Li, Y. Takahashi, A. Scavo, B. Brandt, D. Nguyen, P. Rieu, J.I. Schroeder, Abscisic acidinduced degradation of Arabidopsis guanine nucleotide exchange factor requires calcium-dependent protein kinases, Proc. Natl. Acad. Sci. 115 (2018) E4522-E4531.

[55] C. Huang, Y. Yan, H. Zhao, Y. Ye, Y. Cao, Arabidopsis CPK5 phosphorylates the chitin receptor LYK5 to regulate plant innate immunity, Front. Plant Sci. 11 (2020) 702.

[56] L. Yang, Y. Zhang, R. Guan, S. Li, X. Xu, S. Zhang, J. Xu, Co-regulation of indole glucosinolates and camalexin biosynthesis by CPK5/CPK6 and MPK3/MPK6 signaling pathways, J. Integr. Plant Biol. 62 (2020) 1780-1796.

[57] Z. Hong, S.Y. Bednarek, E. Blumwald, I. Hwang, G. Jurgens, D. Menzel, K.W. Osteryoung, N. V. Raikhel, K. Shinozaki, N. Tsutsumi, D.P.S. Verma, A unified nomenclature for Arabidopsis dynamin-related large GTPases based on homology and possible functions, Plant Mol. Biol. 53 (2003) 261-265.

[58] J.M. Smith, M.E. Leslie, S.J. Robinson, D.A. Korasick, T. Zhang, S.K. Backues, P. V. Cornish, A.J. Koo, S.Y. Bednarek, A. Heese, Loss of Arabidopsis thaliana dynaminrelated protein $2 \mathrm{~B}$ reveals separation of innate immune signaling pathways, PLoS 
Pathog. 10 (2014) e1004578.

[59] T. Sato, S. Maekawa, S. Yasuda, Y. Domeki, K. Sueyoshi, M. Fujiwara, Y. Fukao, D.B. Goto, J. Yamaguchi, Identification of 14-3-3 proteins as a target of ATL31 ubiquitin ligase, a regulator of the C/N response in Arabidopsis, Plant J. 68 (2011) 137-146.

[60] T. Sato, S. Maekawa, S. Yasuda, Y. Sonoda, E. Katoh, T. Ichikawa, M. Nakazawa, M. Seki, K. Shinozaki, M. Matsui, D.B. Goto, A. Ikeda, J. Yamaguchi, CNI1/ATL31, a RINGtype ubiquitin ligase that functions in the carbon/nitrogen response for growth phase transition in Arabidopsis seedlings, Plant J. 60 (2009) 852-864.

[61] S. Yasuda, S. Aoyama, Y. Hasegawa, T. Sato, J. Yamaguchi, Arabidopsis CBL-interacting protein kinases regulate carbon/nitrogen-nutrient response by phosphorylating ubiquitin ligase ATL31, Mol. Plant. 10 (2017) 605-618.

[62] G. Xu, W. Chen, L. Song, Q. Chen, H. Zhang, H. Liao, G. Zhao, F. Lin, H. Zhou, F. Yu, FERONIA phosphorylates E3 ubiquitin ligase ATL6 to modulate the stability of 14-3-3 proteins in response to the carbon/nitrogen ratio, J. Exp. Bot. 70 (2019) 6375-6388.

[63] M. Yoshii, M. Nishikiori, K. Tomita, N. Yoshioka, R. Kozuka, S. Naito, M. Ishikawa, The Arabidopsis cucumovirus multiplication 1 and 2 loci encode translation initiation factors 4E and 4G, J. Virol. 78 (2004) 6102-6111.

[64] V. Nicaise, J.L. Gallois, F. Chafiai, L.M. Allen, V. Schurdi-Levraud, K.S. Browning, T. Candresse, C. Caranta, O. Le Gall, S. German-Retana, Coordinated and selective recruitment of elF4E and elF4G factors for potyvirus infection in Arabidopsis thaliana, FEBS Lett. 581 (2007) 1041-1046.

[65] K. Hyodo, K. Hashimoto, K. Kuchitsu, N. Suzuki, T. Okuno, Harnessing host ROSgenerating machinery for the robust genome replication of a plant RNA virus, Proc. Natl. Acad. Sci. 114 (2017) E1282-E1290.

[66] K. Hyodo, N. Suzuki, T. Okuno, Hijacking a host scaffold protein, RACK1, for replication of a plant RNA virus, New Phytol. 221 (2019) 935-945.

[67] A. Perraki, J. Gronnier, P. Gouguet, M. Boudsocq, A.-F. Deroubaix, V. Simon, S. German-Retana, A. Legrand, B. Habenstein, C. Zipfel, E. Bayer, S. Mongrand, V. 
Germain, REM1.3's phospho-status defines its plasma membrane nanodomain organization and activity in restricting PVX cell-to-cell movement, PLoS Pathog. 14 (2018) e1007378. 
A

\begin{tabular}{|c|c|c|c|c|}
\hline \multirow{3}{*}{ Dex } & \multirow{2}{*}{\multicolumn{3}{|c|}{$\begin{array}{ccc}\text { Dex:CPK5ac-WT } & \begin{array}{c}\text { Dex: } \\
\text { CPK5ac- } \\
\text { dead }\end{array} \\
\# 1 & \# 2\end{array}$}} & \\
\hline & & & & \\
\hline & +-+ & & & \\
\hline PK activity & $=$ & $=\quad=$ & & histone \\
\hline anti-HA & - & $=$ & & - СРК5ас-HA \\
\hline massie & 81 & $8 ! 1$ & & rubisco \\
\hline
\end{tabular}

B
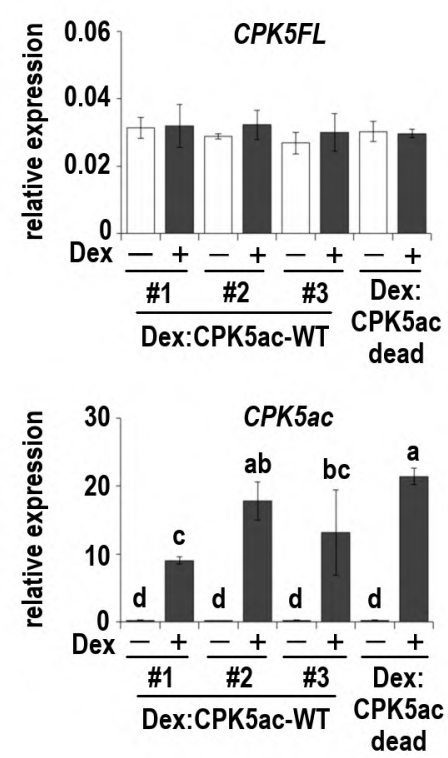

Figure 1. Molecular characterization of Dex:CPK5ac-HA lines.

(A) CPK5 activity was analyzed in WT plants, Dex:CPK5ac-HA WT and dead lines, upon mock (-) and Dex (+) treatment for $6 \mathrm{~h}$, after immunoprecipitation with anti-HA antibody and using histone as a substrate (upper panel). The expression of CPK5acHA was analyzed by western-blot with anti-HA antibody (middle panel) and equal protein loading was monitored by coomassie staining (lower panel).

(B) The expression of endogenous (CPK5FL) and transgene (CPK5ac) CPK5 was analyzed by qRT-PCR in Dex:CPK5ac-HA WT and dead lines, upon mock (-) and Dex (+) treatment for $6 \mathrm{~h}$. Values are means $+/$ - SD of three independent biological replicates $(n=3)$. Letters indicate statistical differences (nonparametric multiple comparison test, $p<0.001$ ). No statistical difference was observed for CPK5FL expression. 
A

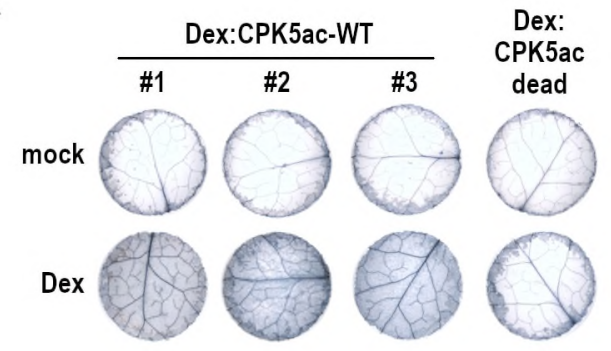

B

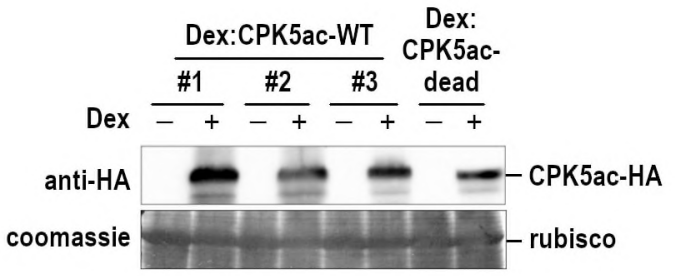

C

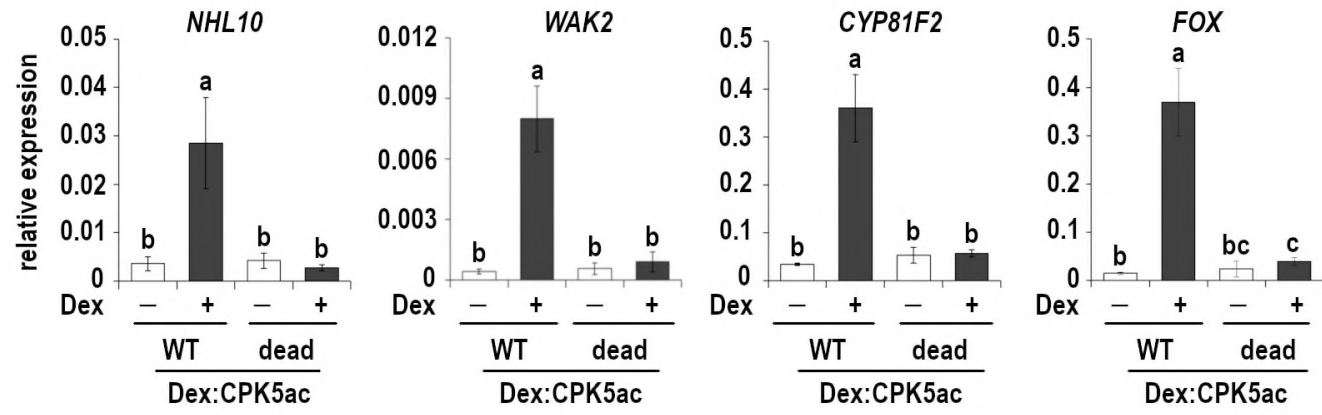

Figure 2. Functional validation of the Dex:CPK5ac-HA lines.

(A) Cell death in leaf disks of Dex:CPK5ac-HA WT and dead lines was monitored by trypan blue staining $48 \mathrm{~h}$ after mock or Dex treatment.

(B) The expression of CPK5ac-HA in the same samples as (A) was analyzed by western-blot with anti-HA antibody. Equal protein loading was monitored by coomassie staining.

(C) The expression of CPK5 target genes was analyzed by qRT-PCR in Dex:CPK5acHA WT and dead lines, upon mock (-) and Dex (+) treatment for $6 \mathrm{~h}$. Values are means $+/$ - SD of five independent biological replicates $(n=5)$. Letters indicate statistical differences (nonparametric multiple comparison test, $p<0.001$ ). 
A

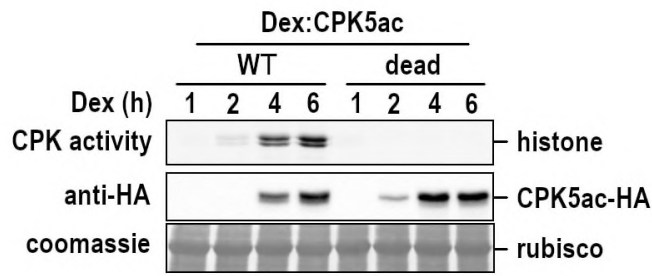

B

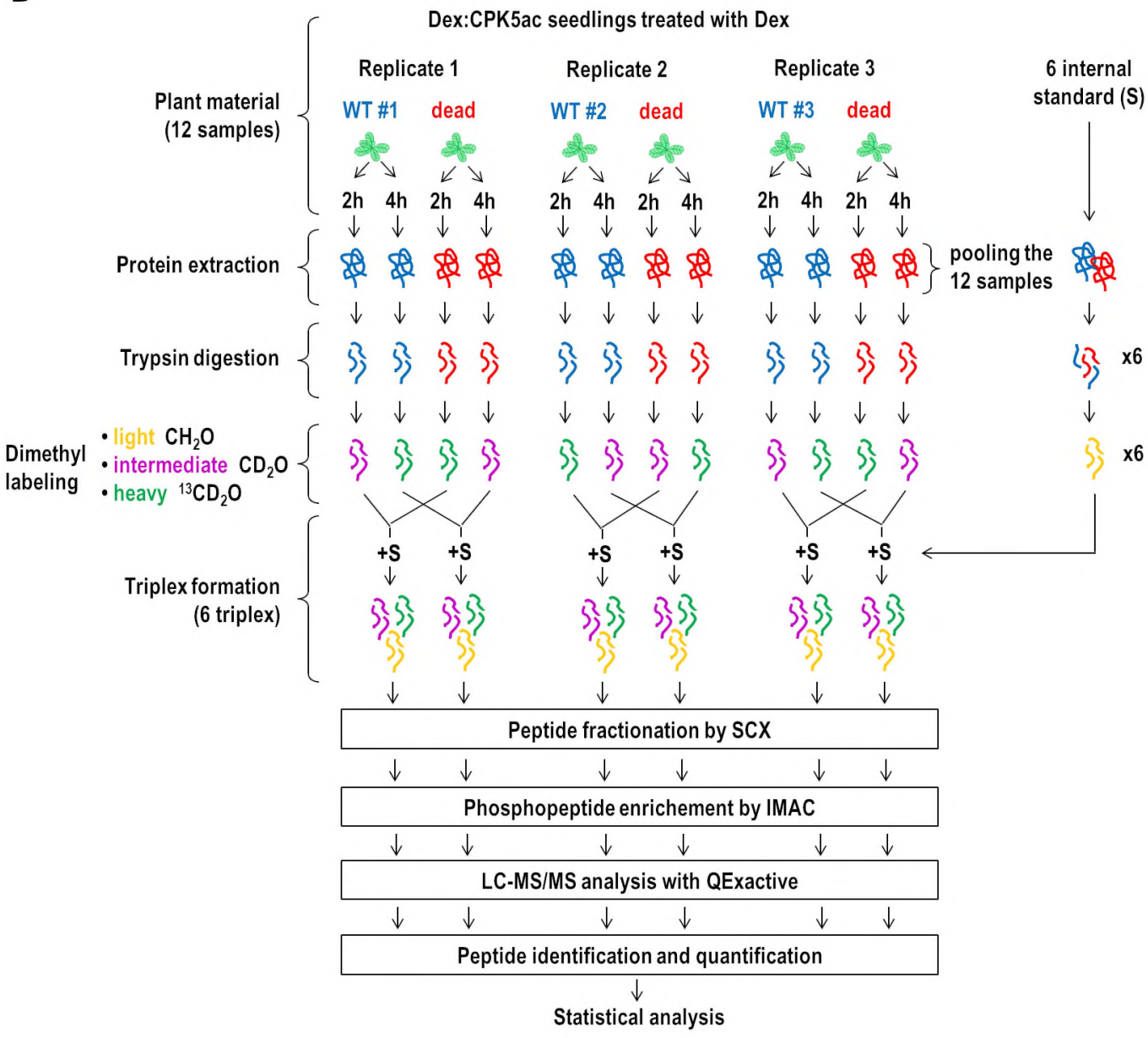

Figure 3. Workflow of the phosphoproteome analysis.

(A) Time-course analysis of CPK5 activity in Dex:CPK5ac-HA WT and dead lines upon Dex treatment, after immunoprecipitation with anti-HA antibody and using histone as a substrate (upper panel). The expression of CPK5ac-HA was analyzed by western-blot with anti-HA antibody (middle panel) and equal protein loading was monitored by coomassie staining (lower panel).

(B) Workflow of the phosphoproteome analysis. The quantification is based on stable isotope dimethyl labeling of the tryptic peptides (either intermediate or heavy labeling). The normalization was performed with the internal standard tagged with light labeling corresponding to the pooling of the $\mathbf{1 2}$ samples in equal amounts. Triplex were formed by mixing for each time point and each biological replicate WT sample, dead sample and internal standard in ratio 1:1:1. 
DRP2B AAAASSWSDNSGTESPSPR

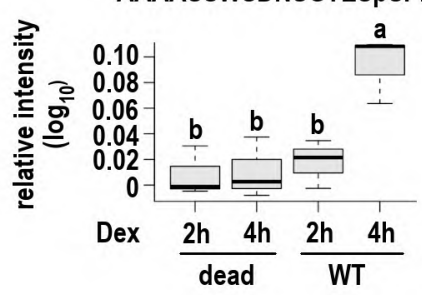

ATL6 ASAVPNSTGpSDSVR

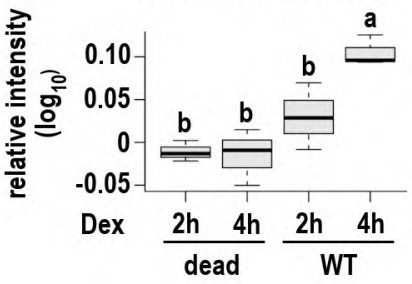

EIF4G QVLQGPSATVNpSPR

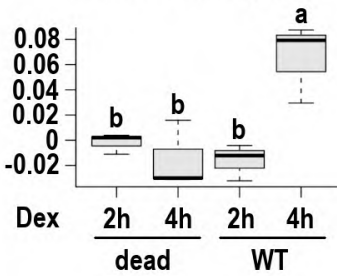

ATL31 PSNSVFVLPR

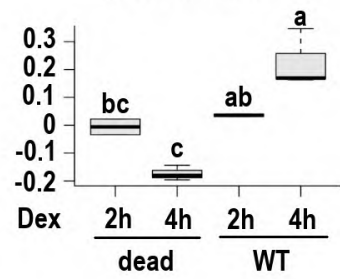

Figure 4. Quantification of the five phosphopeptides specifically accumulated in the Dex:CPK5ac-HA WT line compared to the dead line. The boxplots show the relative abundance (XIC) of each phosphopeptide in Dex:CPK5ac-HA WT and dead lines upon Dex treatment. Letters indicate statistical differences (ANOVA $p<0.01$ followed by Tukey test $p<0.05$ ). The phosphosite within the sequence is indicated by pS. 


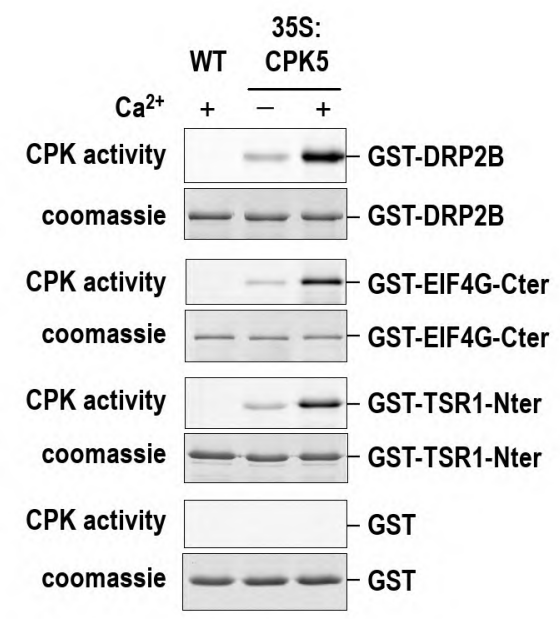

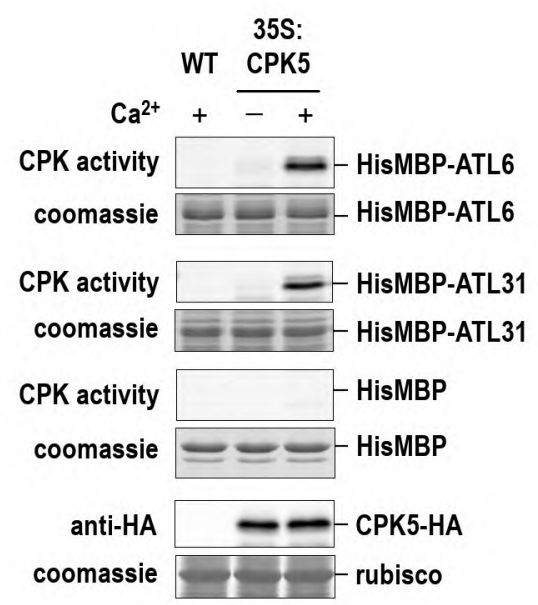

Figure 5. Validation of the candidates as direct substrates of CPK5.

Protein kinase assay was performed in the presence (+) or absence (-) of calcium with CPK5-HA immunoprecipitated from 35S-CPK5-HA seedlings and each candidate produced as recombinant protein fused to either GST or HisMBP. Immunoprecipitation from WT plants was used as a negative control, as well as GST and HisMBP substrates. The protein amount of each candidate was controlled by coomassie staining of the gel and CPK5HA expression was monitored by western-blot anti-HA. 


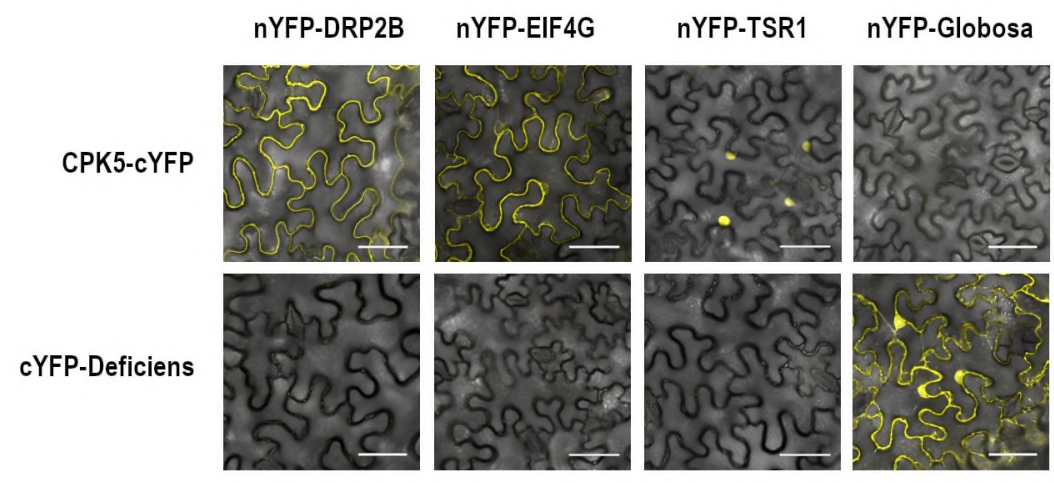

Figure 6. In vivo interaction of CPK5 and the candidates by BiFC.

CPK5 fused to CYFP and the candidates fused to nYFP were coexpressed in tobacco leaves. The Globosa/Deficiens interaction in the cytosol and nucleus was used as a positive control.

Fluorescence was observed at $2 \mathrm{dpi}$ under a confocal microscope. The pictures represent the merged images of fluorescence and bright field. Scale bar $=\mathbf{5 0} \boldsymbol{\mu m}$. 
A

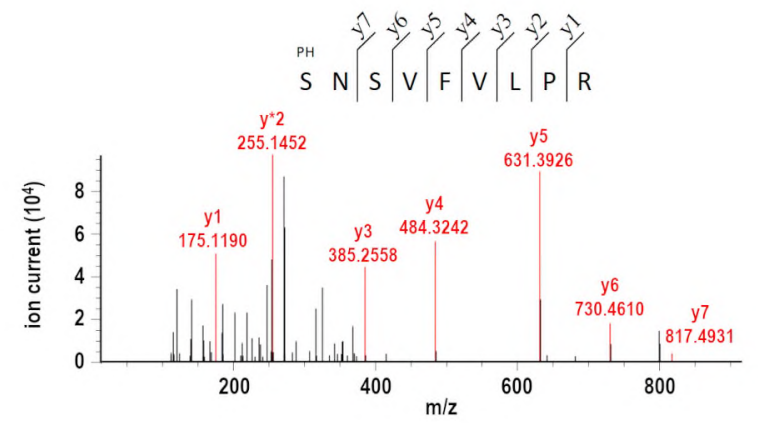

B

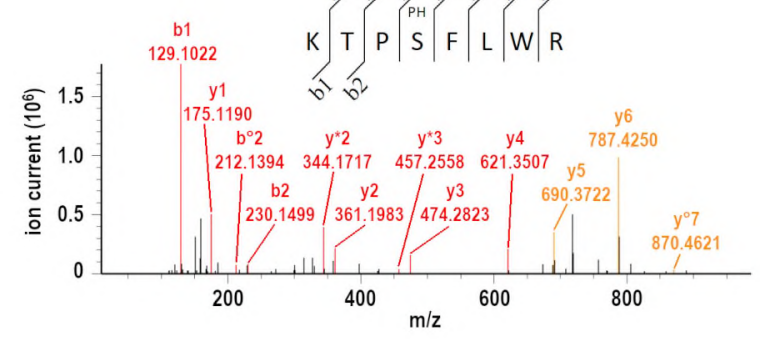

C

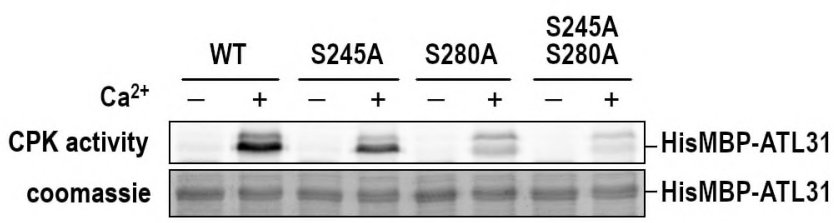

Figure 7. Validation of ATL31 target sites by CPK5.

(A, B) MS/MS spectrum of the two phosphopeptides identified in ATL31 after in vitro kinase assay with CPK5: 245pSNSVFVLPR 253 containing S245 (A) and 277 KTPpSFLWR 284 containing $S 280$ (B). (C) Protein kinase assay was performed in the presence $(+)$ or absence (-) of calcium with CPK5-HA immunoprecipitated from 35S-CPK5-HA seedlings and recombinant HisMBP-ATL31 WT and mutated forms. The protein amount of each substrate was controlled by coomassie staining of the gel. 
Table 1. List of putative in vivo CPK5 substrates

\begin{tabular}{|c|c|c|c|c|c|}
\hline AGI & protein & TAIR annotation & Phosphopeptide sequence & $\begin{array}{c}\text { phospho- } \\
\text { site }\end{array}$ & $\begin{array}{c}\mathrm{CDPK} \\
\text { motif }\end{array}$ \\
\hline At1g59610 & $\begin{array}{l}\text { DRP2B, } \\
\text { ADL3 }\end{array}$ & $\begin{array}{l}\text { dynamin-related protein } \\
2 \mathrm{~B} \text {, Dynamin-like } 3\end{array}$ & AAAASSWSDNSGTESpSPR & S844 & yes \\
\hline At3g60240 & $\begin{array}{l}\text { EIF4G, } \\
\text { CUM2 }\end{array}$ & $\begin{array}{c}\text { eukaryotic translation } \\
\text { initiation factor } 4 \mathrm{G}, \\
\text { Cucumovirus } \\
\text { multiplication } 2 \\
\end{array}$ & QVLQGPSATVNpSPR & S1525 & yes \\
\hline At1g42440 & $\begin{array}{l}\text { TSR1- } \\
\text { like }\end{array}$ & $\begin{array}{l}\text { pre-rRNA-processing } \\
\text { TSR1-like protein }\end{array}$ & $\begin{array}{c}\text { GEDSNQEGMYDQEFEDDG } \\
\text { KpSLNLR }\end{array}$ & S437 & no \\
\hline At3g05200 & ATL6 & $\begin{array}{c}\text { Arabidopsis toxicos en } \\
\text { levadura 6, RING-H2 type } \\
\text { E3 ubiquitin ligase }\end{array}$ & ASAVPNSTGpSDSVR & S341 & no \\
\hline At5g27420 & $\begin{array}{l}\text { ATL31, } \\
\text { CNI1 }\end{array}$ & $\begin{array}{c}\text { Arabidopsis toxicos en } \\
\text { levadura 31, } \\
\text { carbon/nitrogen } \\
\text { insensitive 1, RING-H2 } \\
\text { type E3 ubiquitin ligase } \\
\end{array}$ & pSNSVFVLPR & S245 & no \\
\hline
\end{tabular}



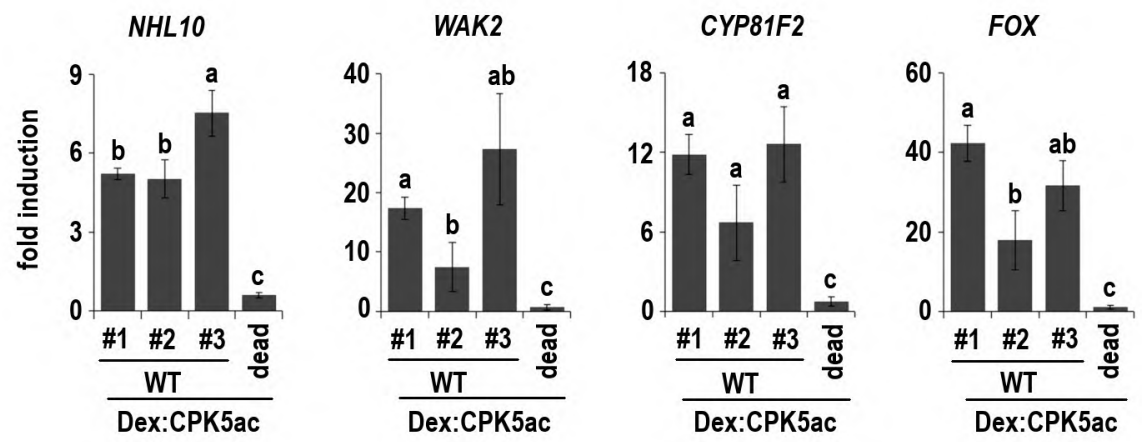

Supplementary Figure 1. Induction of CPK5 target genes in transgenic Dex:CPK5ac lines.

The expression of CPK5 target genes was analyzed by qRT-PCR in Dex:CPK5ac-HA WT and dead lines, upon mock and Dex treatment for 6 $\mathrm{h}$, and presented as the ratio between Dex and mock values. Values are means $+/$ - SD of 3 independent biological replicates $(n=3)$. Letters indicate statistical differences (nonparametric multiple comparison test, $p<0.001$ ). 


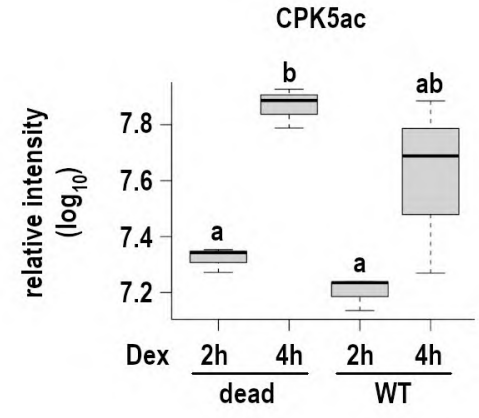

Supplementary Figure 2. Quantification of the only protein specifically accumulated upon Dex treatment in Dex lines.

The boxplots show the relative abundance (XIC) of CPK5ac in Dex:CPK5ac-HA WT and dead lines upon Dex treatment. Letters indicate statistical differences (ANOVA $p<0.01$ followed by Tukey test $p<0.05$ ). 
A

RYPSDPAQNGEDSSGSGGSSR

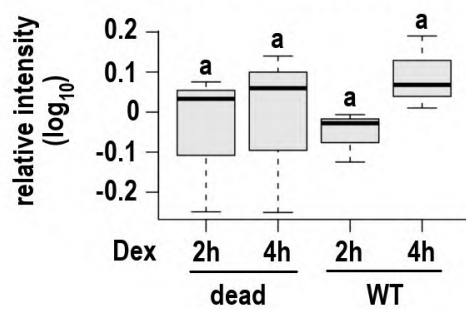

EIF4G

STEGSSHASSEISGSPSPQEK

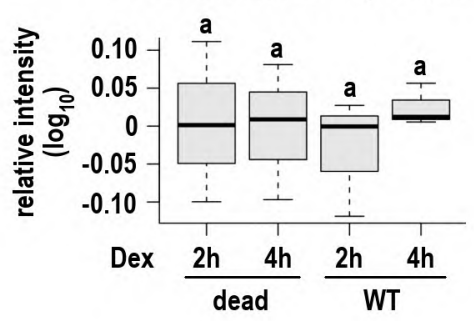

DRP2B

YSDPAQNGEDPSSGSGGSR

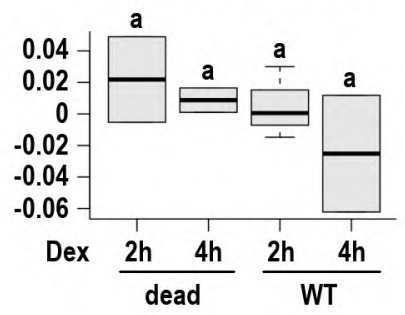

ATL 6

PSHTTGHSVVQPGECTER

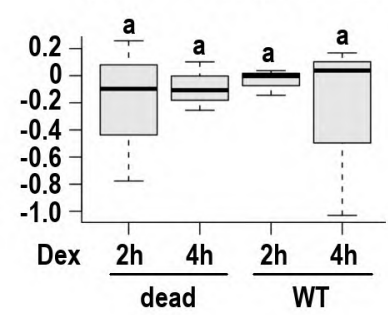

B

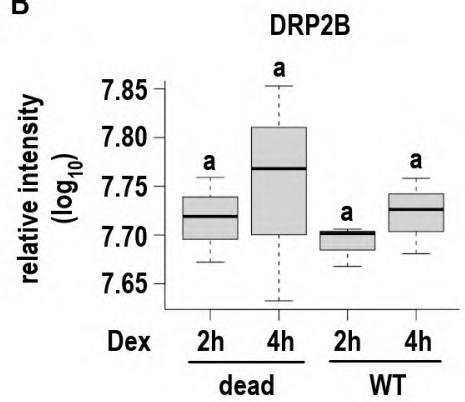

EIF4G

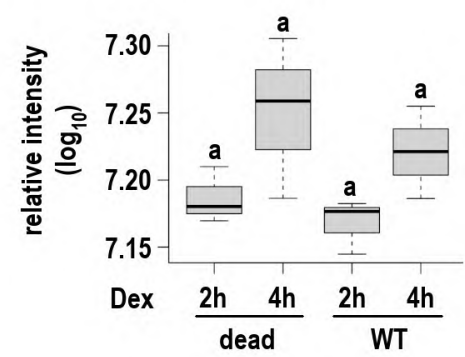

Supplementary Figure 3. Quantification of phosphopeptides and proteins not altered in Dex:CPK5ac-HA WT and dead lines, among the 5 substrate candidates.

(A) The boxplots show the relative abundance (XIC) of each phosphopeptide in Dex:CPK5ac-HA WT and dead lines upon Dex treatment. The phosphosite within the sequence is indicated by $\mathrm{pS}$. (B) The boxplots show the relative abundance (XIC) of target proteins in Dex:CPK5ac-HA WT and dead lines upon Dex treatment. Letters indicate no statistical difference (ANOVA p $<0.01$ followed by Tukey test $p<0.05)$. 
YFP

+ chlorophyll

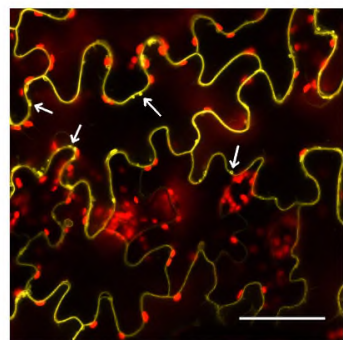

YFP

+ bright field

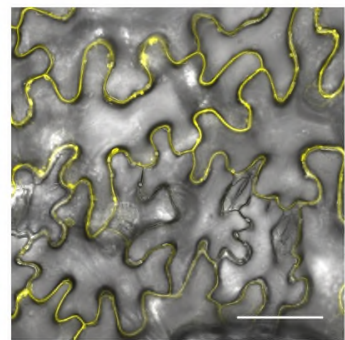

Supplementary Figure 4. DRP2B and CPK5 interact in vivo in plasma membrane and vesicle-like structures.

CPK5 fused to CYFP and DRP2B fused to nYFP were co-expressed in tobacco leaves. Fluorescence was observed at 2 dpi under a confocal microscope. YFP signal was observed as described in the Material and Methods section. Chlorophyll signal was observed with an excitation wavelength of $514 \mathrm{~nm}$ and a detection wavelength between $637 \mathrm{~nm}$ and $721 \mathrm{~nm}$. The pictures represent the merged images of YFP and chlorophyll fluorescence (left panel) and YFP fluorescence and bright field (right panel). The arrows indicate examples of vesicle-like structures which are clearly distinct from red chloroplasts. Scale bar $=\mathbf{5 0} \mu \mathrm{m}$. 


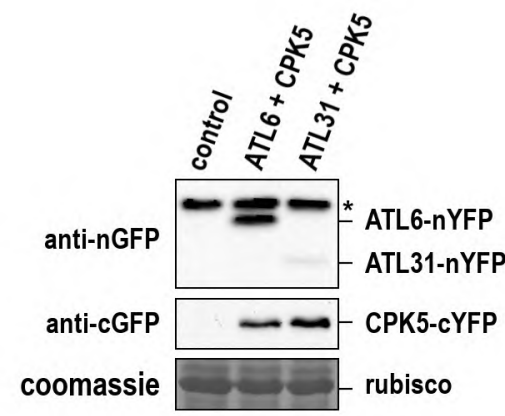

Supplementary Figure 5. Expression of ATL6/31-nYFP and CPK5-cYFP in tobacco leaves.

Protein extracts from tobacco leaves untransfected (control) and co-transected with CPK5-cYFP + ATL6nYFP or ATL31-nYFP were analyzed by western-blot with anti-nGFP and anti-cGFP. Protein loading was controlled by coomassie staining of the membrane. The star indicates a non-specific signal detected by anti-nGFP antibody. 
RBOHD

TSPSAAIHALK

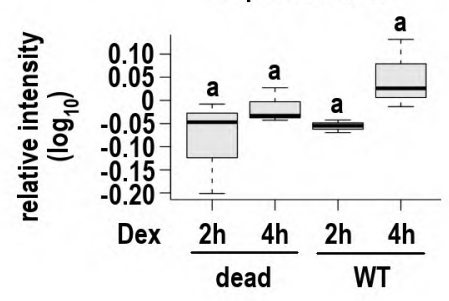

Supplementary Figure 6. Quantification of the S163-containing phosphopeptide of RBOHD in Dex:CPK5ac-HA WT and dead lines.

The boxplot shows the relative abundance $(X I C)$ of the phosphopeptide in Dex:CPK5ac-HA WT and dead lines upon Dex treatment. Letters indicate no statistical difference (ANOVA $p<0.01$ followed by Tukey test $p<0.05)$. The $S 163$ is indicated by $\mathrm{pS}$ in the peptide sequence. 
Supplementary Table S1. Sequence of primers used for cloning. The type of cloning is indicated in brackets: restriction enzyme used for classical cloning, GW for Gateway ${ }^{\mathrm{TM}}$ cloning, NEB for NEBuilder ${ }^{\circledR}$ cloning. For truncated forms, the amino acid numbers are indicated. The cloning sequence contains the stop codon unless indicated.

\begin{tabular}{|c|c|c|c|c|}
\hline Gene & AGI & vector & $\begin{array}{c}\text { Primer } \\
\text { For/Rev } \\
\text { (cloning } \\
\text { site) }\end{array}$ & Sequence \\
\hline \multirow{4}{*}{ CPK5 } & \multirow{4}{*}{ At4g35310 } & \multirow[b]{2}{*}{ Dex } & For (Xhol) & CCGCTCGAGATGGGCAATTCTTGCC \\
\hline & & & $\begin{array}{l}\text { Rev (Stul, } \\
1-360 \mathrm{aa})\end{array}$ & GAAGGCCTAACACCATTCTCACAGATC \\
\hline & & \multirow{2}{*}{$\begin{array}{l}\text { pDONR } \\
207\end{array}$} & For (GW) & $\begin{array}{l}\text { GGGGACAAGTTTGTACAAAAAAGCAGGCTTCGA } \\
\text { AGGAGATAGAACCATGGGCAATTCTTGCC }\end{array}$ \\
\hline & & & $\operatorname{Rev}(\mathrm{GW})$ & $\begin{array}{l}\text { GGGGACCACTTTGTACAAGAAAGCTGGGTCTC } \\
\text { CACCTCCGGATCACGCGTCTCTCATGCTA }\end{array}$ \\
\hline \multirow{4}{*}{ DRP2B } & \multirow{4}{*}{ At1g59610 } & \multirow{2}{*}{$\begin{array}{l}\text { pGEX- } \\
2 T\end{array}$} & For (NEB) & $\begin{array}{l}\text { CTCTCCCCTTGCTCCGTGGATCCATGGAGGCG } \\
\text { ATCGATGAG }\end{array}$ \\
\hline & & & $\operatorname{Rev}(N E B)$ & $\begin{array}{l}\text { GAGATGAGCTTCTGCTCAGGCCTATACCTGTAA } \\
\text { GATGATCC }\end{array}$ \\
\hline & & \multirow{2}{*}{$\begin{array}{l}\text { pDONR } \\
207\end{array}$} & For (GW) & $\begin{array}{l}\text { GGGGACAAGTTTGTACAAAAAAGCAGGCTTCGA } \\
\text { AGGAGATAGAACCATGGAGGCGATCGATGAG }\end{array}$ \\
\hline & & & $\operatorname{Rev}(\mathrm{GW})$ & $\begin{array}{l}\text { GGGGACCACTTTGTACAAGAAAGCTGGGTCTC } \\
\text { CACCTCCGGATCAATACCTGTAAGATGATCC }\end{array}$ \\
\hline \multirow{3}{*}{ EiF4G } & \multirow{3}{*}{ At3g60240 } & \multirow{3}{*}{$\begin{array}{l}\text { pDONR } \\
207\end{array}$} & For (GW) & $\begin{array}{l}\text { GGGGACAAGTTTGTACAAAAAAGCAGGCTTCGA } \\
\text { AGGAGATAGAACCATGTCCTACAATCAATCC }\end{array}$ \\
\hline & & & $\begin{array}{l}\text { For }(\mathrm{GW}, \\
916-1727 \\
\text { aa) }\end{array}$ & $\begin{array}{l}\text { GGGGACAAGTTTGTACAAAAAAGCAGGCTTCGA } \\
\text { AGGAGATAGAACCACAGAAAAGAAGTACTCC }\end{array}$ \\
\hline & & & $\operatorname{Rev}(\mathrm{GW})$ & $\begin{array}{l}\text { GGGGACCACTTTGTACAAGAAAGCTGGGTCTC } \\
\text { CACCTCCGGATCAAGTAAATTTCTCTAATAT }\end{array}$ \\
\hline \multirow{3}{*}{$\begin{array}{l}\text { TSR1- } \\
\text { like }\end{array}$} & \multirow{3}{*}{ At1g42440 } & \multirow{3}{*}{$\begin{array}{l}\text { pDONR } \\
207\end{array}$} & For (GW) & $\begin{array}{l}\text { GGGGACAAGTTTGTACAAAAAAGCAGGCTTCGA } \\
\text { AGGAGATAGAACCATGGGACGCTCTCGAGTTC }\end{array}$ \\
\hline & & & $\operatorname{Rev}(\mathrm{GW})$ & $\begin{array}{l}\text { GGGGACCACTTTGTACAAGAAAGCTGGGTCTC } \\
\text { CACCTCCGGATCATACTTCATCTGGAAATTC }\end{array}$ \\
\hline & & & $\begin{array}{l}\text { Rev (GW, } \\
1-485 \mathrm{aa})\end{array}$ & $\begin{array}{l}\text { GGGGACCACTTTGTACAAGAAAGCTGGGTCTC } \\
\text { CACCTCCGGATCATACTTCATCTGGAAATTC }\end{array}$ \\
\hline \multirow{3}{*}{ ATL6 } & \multirow{3}{*}{ At3g05200 } & \multirow{3}{*}{$\begin{array}{l}\text { pDONR } \\
207\end{array}$} & For (GW) & $\begin{array}{l}\text { GGGGACAAGTTTGTACAAAAAAGCAGGCTTCGA } \\
\text { AGGAGATAGAACCATGAGAAGCTCCGATCAT }\end{array}$ \\
\hline & & & $\operatorname{Rev}(\mathrm{GW})$ & $\begin{array}{l}\text { GGGGACCACTTTGTACAAGAAAGCTGGGT } \\
\text { CTCCACCTCCGGATCAAACCGGTAATCTCA } \\
\text { CCGA }\end{array}$ \\
\hline & & & $\begin{array}{l}\operatorname{Rev}(\mathrm{GW}, \\
\text { no stop) }\end{array}$ & $\begin{array}{l}\text { GGGGACCACTTTGTACAAGAAAGCTGGGT } \\
\text { CTCCACCTCCGGAAACCGGTAATCTCACC } \\
\text { GA }\end{array}$ \\
\hline \multirow{2}{*}{ ATL31 } & \multirow{2}{*}{ At5g27420 } & \multirow{2}{*}{$\begin{array}{l}\text { pDONR } \\
207\end{array}$} & For (GW) & $\begin{array}{l}\text { GGGGACAAGTTTGTACAAAAAAGCAGGCTT } \\
\text { CGAAGGAGATAGAACCATGGATCCCATAAA } \\
\text { ACAC }\end{array}$ \\
\hline & & & $\operatorname{Rev}(\mathrm{GW})$ & $\begin{array}{l}\text { GGGGACCACTTTGTACAAGAAAGCTGGGT } \\
\text { CTCCACCTCCGGATCAAACCGGTAGCCTAA } \\
\text { GG }\end{array}$ \\
\hline
\end{tabular}




\begin{tabular}{|l|l|l|l|}
\hline & & $\begin{array}{c}\text { Rev (GW, } \\
\text { no stop) }\end{array}$ & $\begin{array}{l}\text { GGGGACCACTTTGTACAAGAAAGCTGGGT } \\
\text { CTCCACCTCCGGAAACCGGTAGCCTAAGG } \\
\text { GA }\end{array}$ \\
\hline
\end{tabular}

Supplementary Table S2. Sequence of primers used for mutagenesis. The mutated site is indicated in brackets.

\begin{tabular}{|c|c|c|c|}
\hline Gene & AGI & $\begin{array}{c}\text { Primer For/Rev } \\
\text { (mutation) }\end{array}$ & Sequence \\
\hline \multirow{4}{*}{ CPK5 } & \multirow{4}{*}{ At4g35310 } & For (D221A) & GTGTGATGCATAGAGCCTTGAAGCCTGAGAA \\
\hline & & $\operatorname{Rev}(\mathrm{D} 221 \mathrm{~A})$ & TTCTCAGGCTTCAAGGCTCTATGCATCACAC \\
\hline & & For (stop) & GCATGAGAGACGCGGGGTCCGGAGGTGGAGAC \\
\hline & & $\operatorname{Rev}($ stop) & GTCTCCACCTCCGGACCCCGCGTCTCTCATGC \\
\hline \multirow{4}{*}{ ATL31 } & \multirow{4}{*}{ At5g27420 } & For (S245A) & GGAAATTGAACCGGGCGAATAGTGTTTTTG \\
\hline & & $\operatorname{Rev}(\mathrm{S} 245 \mathrm{~A})$ & CAAAAACACTATTCGCCCGGTTCAATTTCC \\
\hline & & For (S280A) & TCCGTAAAACTCCGGCGTTTCTATGGAGGA \\
\hline & & $\operatorname{Rev}(\mathrm{S} 280 \mathrm{~A})$ & TCCTCCATAGAAACGCCGGAGTTTTACGGA \\
\hline
\end{tabular}

